\title{
Year of Cataloging Research
}

\section{Cataloging and Classification}

\section{Review of the Literature 2007-8}

\section{By Sydney Chambers and Carolynne Myall}

This paper surveys library literature on cataloging and classification published in 2007-8, indicating its extent and range in terms of types of literature, major subject areas, and themes. The paper reviews pertinent literature in the following areas: the future of bibliographic control, general cataloging standards and texts, Functional Requirements for Bibliographic Records (FRBR), cataloging varied resources, metadata and cataloging in the Web world, classification and subject access, questions of diversity and diverse perspectives, additional reports of practice and research, catalogers' education and careers, keeping current through columns and blogs, and cataloging history.

Speculations, questions, anxieties, and excitement about the roles and possible futures of cataloging and catalogers underlie much of the literature of cataloging and classification during 2007-8. While many publications focused on the future and the significant changes that emerging trends may require, other contributions addressed a variety of aspects of practice-many immediate and practical-and underlying philosophy. Topics in the history of bibliographic control and in representing diverse and global perspectives in cataloging data also were strongly in evidence. The objectives of this paper are to

- survey the extensive and varied literature of cataloging and classification during 2007-8;

- indicate the range of this literature in terms of types of publications, including scholarly works but also publications intended to aid practitioners and communicate cataloging issues to noncatalogers;

- identify major subject areas and themes; and

- recommend substantive contributions in these areas, along with more ephemeral but worthy contributions useful to catalogers struggling to keep cataloging alive and useful in a period of scrutiny, uncertainty, multiple initiatives, and change.

\section{Research Method}

Using a bibliographic management program, we began the project by creating a database of citations with folders for 2007 and 2008. To do this, we searched several online databases, including Library Literature and Information Science Full Text; Library, Information Science, and Technology Abstracts with Full Text; Online Computer Library Center (OCLC) WorldCat; and Dissertations and Theses Online. Search strategies included both keyword and subject heading searches, using many pertinent terms, such as bibliographic control, cataloging, 
classification, RDA: Resource Description and Access, and Functional Requirements for Bibliographic Records (FRBR). We also searched Google Books and Google itself, athough most of our Web searching followed the strategy of following links that led from one document or blog to another. We favored more stable or persistent formats of resources, since some Web drafts and documents appeared and then were removed or relocated, a problematic characteristic for long-term identification.

In an initial review, citations for news articles and reviews for each year were moved to separate folders. We used citations for reviews to identify monographic publications; citations for news articles were reviewed to identify major concerns and events. Citations for works evidently out-of-scope or in languages we could not read were moved to "holding pen" folders. Then we began a more thorough review of the remaining citations. Ultimately, we limited the scope to English-language resources, particularly those that applied to North American libraries. The approximate numbers of unique citations remaining were 444 for 2007 and 350 for 2008. ${ }^{1}$ Next, we worked through the citations and abstracts, obtained print or online copies, assembled a file of printed resources, and attempted to cull further. With the shifting boundaries of cataloging, determining whether an article was in-scope was not always easy, even after an initial review. Acknowledging the difficulties posed by the indeterminate boundaries of the field at the moment, we agreed that for a contribution to be defined as in-scope, it must have a library cataloging or classification application or orientation, or it must represent an application of library cataloging methods to a problem in the broader universe of information (e.g., Yahoo!). User studies were similarly limited by this definition of scope. Since we were interested in the distribution of cataloging literature across many publications, we next arranged journal articles by publication title and cross-tabulated for subject area and types of literature using lists and colored tabs (a primitive method, but effective for the visually oriented).

Our file grew to include 468 articles from 104 periodicals, plus many new or revised cataloging standards, such as Descriptive Cataloging of Rare Materials (Books) (DCRM (B)), as well as monographs, reports, theses, and Web documents. ${ }^{2}$ While we emphasized scholarly articles, reports, and monographs intended for specialists in cataloging and classification, we also considered literature directed toward wider audiences in librarianship. We were struck by the large number of possibly pertinent resources—surely a testimony to the high level of activity and interest in bibliographic organization - and by their appearance in many different publications.

Evaluation and selection was a time-consuming undertaking. We attempted to include some contributions of interest to all parts of the cataloging community. While each of us concentrated on specific areas, we reviewed each other's selections and suggested works for inclusion or removal. In each area of the literature discussed in this review, inclusions are representative, not comprehensive; as any cataloger could predict, many items legitimately might have been placed in more than one category. Despite our best efforts to include all pertinent materials in our search, some works no doubt eluded us, and many valuable contributions could not be included because of space constraints, to our great regret. Finally, any selection from a large number of works will reflect the interests and tastes of the selectors. In particular, our current experience as practitioners in mid-size academic libraries rather than in research libraries or as information studies faculty, and our past experience in other types of libraries, may have influenced our perceptions and choices.

The most immediately prominent contribution to cataloging literature was, we believe, the report of the Library of Congress Working Group on the Future of Bibliographic Control (LCWG); it raised themes of change and adaptation to new conditions that appeared throughout the literature. ${ }^{3}$ Also prominent in the literature were themes of cataloging tradition as well as its objectives, methods, and values, and their continuing pertinence in the emerging environment. These two strands of thought—and the dialogue between them-provide the structure for this paper, which begins with the LCWG report and the future of cataloging and closes with contributions on cataloging and classification history.

\section{The Future(s) of Bibliographic Control}

In April 2006, the Library of Congress (LC) announced that it would no longer create or maintain authority records for series. This unanticipated announcement provoked an apparently unanticipated uproar in the library community. The LC, while postponing but not rescinding its series decision, responded to the concerns of the community by appointing the LCWG, intended to be broadly representative, to consider the long-term future of bibliographic control in the twenty-first century.

The LCWG held its first meeting in November 2006. Over the next year, the LCWG solicited opinions on its website, held regional sessions available to others via webcast, participated in a meeting hosted by the American Library Association (ALA), issued a draft report, and gathered 135 pages of written comments, among other activities, to promote discussion at national and local levels. On January 9 , 2008, the LCWG delivered to the LC what was probably the most widely read and debated contribution to cataloging literature during this two-year period: the LCWG's final report, On the Record. ${ }^{4}$ 
Presenting more than one hundred specific recommendations, On the Record was based on three guiding principles or redefinitions: first, that bibliographic control was broader than library cataloging; second, that the bibliographic universe now extended beyond libraries and publishers to include creators, vendors, distributors, users, and other groups across various kinds of boundaries; and third, that the LC, while still playing a unique role in the U.S. library community, could not continue to perform all of its traditional functions under its current conditions and legislative mandate. Following these principles, LCWG envisioned the future of bibliographic control as

collaborative, decentralized, international in scope, and Web-based. Its realization will occur in cooperation with the private sector, and with the active collaboration of library users. Data will be gathered from multiple sources; change will happen quickly; and bibliographic control will be dynamic, not static. $^{5}$

The LCWG organized its specific recommendations under five general proposals: increase the efficiency of bibliographic production and maintenance; enhance access to rare, unique, and other special hidden materials; position our technology for the future; position our community for the future; and strengthen the library and information science profession. At the macro level, some of the general recommendations seemed mostly unexceptionable. As the literature attested, many libraries were already engaged in creating a more collaborative cataloging future by increasing their contributions to cooperative efforts. ${ }^{6}$ And what cataloger could disagree in principle, if not in specifics, with recommendation 4.3, "Optimize LCSH for Use and Reuse"?7 For that matter, who could deny that libraries were no longer the primary element of the information universe, or that library catalogs were not the starting point for most information-seekers in the digital environment? Taken collectively, though, the LCWG's recommendations, in Hill's words, might require "us to take up residence in an alternate universe, with new understandings, new perspectives, and new responsibilities," a disconcerting prospect. ${ }^{8}$

The specific recommendations of the report touched on many unresolved issues in cataloging and sparked controversies in a number of areas and from a number of points of view. For example, the report recommended that libraries invest more local effort in "exposing to more users rare and unique materials held by libraries that are currently hidden from view," a presumed benefit for both local and global users, while it seemed to advocate less response to local needs through making adjustments to bibliographic records, an arguable point for a library with a strong local mission. ${ }^{9}$ Recommendation 3.2.5 proposed a suspension of work on
RDA: Resource Description and Access, the new cataloging code to which much effort had already been devoted, an unpopular suggestion even among those who viewed RDA as imperfect. ${ }^{10}$ Hillmann offered a stimulating discussion of this and other recommendations from the draft version of the LCWG report. ${ }^{11}$ The number and variety of responses to the LCWG's recommendations testified to its identification of key issues, if not to agreement about how to address them. As a snapshot of where leaders in the library community (as represented by the members of the LCWG) thought we were and where we thought we were going, On the Record seemed likely to remain a key document in cataloging and U.S. library history of the early twenty-first century.

Sanchez's Emerging Issues in Academic Library Cataloging \& Technical Services is a different kind of snapshot of the cataloging environment from the LCWG report, but obviously a picture of the same reality. Emerging Issues is a compilation of the results of a survey of nine cataloging and technical services departments in academic libraries of varying nature and size concerning their organization, staffing, the use of new technologies, the transition to metadata standards, and other activities. ${ }^{12}$ Many of the changes and directions reported here anticipated the recommendations of the LCWG report. For example, departments were engaged in a growing number of digital projects within a more diverse metadata environment, and they reported more extensive collaboration with library and nonlibrary colleagues, in their own institutions and beyond.

Another LC publication, issued in 2007, addressed the future of the Cataloging in Publication (CIP) program. CIP Poised for Change, a report prepared by the CIP Review Group (CRG), presented findings from the 2006 CIP surveys of libraries, publishers, and MARC Distribution Service customers (the MARC Distribution Service supports the CIP program as an important means to increase marketing and sales for publishers, as well as to supply standardized cataloging to libraries quickly). ${ }^{13}$ The CRG recommended enhancing the CIP service with enriched records, more cataloging partners, greater timeliness, the inclusion of a wider range of formats, and a user interface for libraries and publishers. One CRG recommendation, "Examine the feasibility of developing an optional ECIP [Electronic CIP] front end that would accommodate a batch ONIX feed of forthcoming books," was close to the LCWG's recommendation 1.1.3.1., "Develop content and format guidelines for submission of ONIX data to the CIP program and require publishers ... to comply." ${ }^{\text {"14 }}$ Both reports, in different ways, supported the importance of availability of bibliographic data early in the supply chain.

The underlying assumptions of the LCWG report and the directions it proposed were not universally accepted in the cataloging literature. In a slightly revised version of a paper read before the LCWG's second meeting, Bade, a 
defender of traditional library cataloging quality standards, took issue with many of the LCWG's assumptions-for example, defining users of libraries as consumers and managers and consequently viewing information management as a technical and industrial process. ${ }^{15}$ Bade proffered that we had choices with regard to these assumptions:

We can choose to understand what happens in libraries according to a theory of transportation in which all data is equal and we simply move it from one place to another, or we can understand work in libraries according to a theory of communication in which we engage readers in conversations about writers and writings, musicians and music, etc. The importance of that choice lies in the fact that we can do either-with radically different consequences. ${ }^{16}$

In "Will the Response of the Library Profession to the Internet Be Self-Immolation?" Yee advised all librarians, not just catalogers, to follow the deliberations of LCWG: "These library leaders have forgotten, or never knew, the fact that expertise in organization of information is at the core of the profession of librarianship." 17 She saw threats to the profession of librarianship not in the Internet, but rather in librarians who did not understand the nature of librarianship or appreciate the value of human intervention in information organization, in library system designers who did not understand the nature of catalog records and searching, and in the failure to recognize the larger implications of relinquishing to commercial interests the intermediary role of libraries in the information provision chain. "On the Record' But Off the Track," by Mann, a defender of the roles of libraries and of the LC specifically in supporting research and scholarship, detailed many objections to the LCWG report. ${ }^{18}$ Mann, a strong proponent of the value of arrays of precoordinated Library of Congress Subject Headings (LCSH) strings in scholarly research, discussed the LCWG report's failure to distinguish between the needs of scholarly and other researchers; inadequate recognition of the value of controlled vocabulary and LCSH arrays, with subdivisions and cross-references, as opposed to keyword retrieval; minimizing of the LC's contributions as a de facto national library; and assignment of higher priority to digitization of textual special collections rather than maintenance of LCSH and Library of Congress Classification, among other objections.

Some contributions to the literature assumed that significant change in cataloging practice must occur in response to changing library priorities and user expectations. In "Utility, Library Priorities, and Cataloging Policies," Banush and LeBlanc defended the application of the philosophical concept of utility - "the pursuit of the greatest happiness for all, the definition of happiness as the pleasure and absence of pain of sentient beings, and the principle of impartiality"to the consideration of cataloging policies within the context of overarching library priorities. ${ }^{19}$ Banush and LeBlanc quoted a question posed by Marcum: "Just how much do we need to continue to spend on carefully constructed catalogs ... in the Age of Google?"20 They observed that "doing the most good for the greatest number of items does not necessarily mean doing the most good for an individual title" and proposed that a "pragmatic, triage-based process of evaluating needs and allocating staff effort allows for a utility-based approach to solving a thorny need-satisfaction problem," then examined the results of "cataloging pragmatism" at their institution. ${ }^{21}$ The authors concluded that in terms of full access to some library resources, their institution's "triage-based strategy may be bibliographically risky, [but] continuing past practices indefinitely also entails its own potential perils." ${ }^{22}$

"Subject Headings in Full-Text Environments: The ECCO Experiment," by Garrett, quoted the same question by Marcum (albeit in a different manifestation) about the necessity for full catalog records in a universe of digital information and keyword searching, but arrived at a different answer. ${ }^{23}$ This case study demonstrated that subject headings on catalog records for digitized historical materials enriched the keyword index. This enrichment enhanced access to the materials because terms and even proper names changed over time and current searches did not necessarily match the terms found in the full-text documents themselves. Garrett concluded, "Meta-vocabulary . . . performs an important hermeneutic and heuristic function in bibliographic search and discovery, across centuries and across languages-and ... even across states of the same language over time." ${ }^{24}$ Bair and Carlson, in "Where Keywords Fail: Using Metadata to Facilitate Digital Humanities Scholarship," also demonstrated the weakness of keyword searching of digitized primary source documents-in this case a set of eight U.S. Civil War diaries. ${ }^{25}$ Misspellings, alternate spellings, regional variations in word usage, errors and lack of knowledge on the part of the diarists, abbreviations, and variations of names all contributed to retrieval difficulties. This project added authorized headings for personal, corporate, and place names and incorporated subject analysis at the word level in the XML markup. The authors noted that "merely scanning and providing full-text keyword searchability may not fully meet the needs of digital humanities scholars. . . The addition of metadata in the form of normalized name headings and topics can greatly enhance the research experience and save the time of users, especially students. ${ }^{.26}$

The future of cataloging and bibliographic control was the explicit focus of many contributions. Simultaneously recognizing and utilizing change in the information environment, while preserving distinctive and valuable aspects of 
the library cataloging tradition, was the underlying challenge addressed in the literature. Responses varied greatly. For example, "The Online Library Catalog: Paradise Lost and Paradise Regained?" by Markey, identified the failures of online catalogs, rejected the idea that cataloging simplification and primary sources would regain users, and proposed an alternate route to catalog improvement. ${ }^{27}$ Markey suggested that in a post-mass-digitization future, probabilistic searching (rather than outdated Boolean-based retrieval), subject cataloging "to take advantage of the user's ability to recognize what they want or do not want during the course of the search," and metadata that enables precise qualification of searches could bring the catalog into prominent use again. ${ }^{28}$ In the meantime, several specific steps would improve catalogs immediately: including data elements that users want to see in brief displays; ranking algorithms that weight summary data such as titles, subject headings, and class numbers; and "integration of online library catalog searching into the larger scenario of information seeking generally," among other proposals. ${ }^{29}$ From another perspective, "Who Moved My Pinakes? Cataloging and Change" by Gross, acknowledged the changes inevitably underway in cataloging and librarianship, but observed, "What has yet to be resolved is whether these changes will actually mean progress and improvement or the gutting of our mission." ${ }^{30}$ Gross objected to the characterization of reactions against recent developments merely as fear of change. In this context, objections might be legitimate defenses against threats to the integrity of cataloging.

\section{General Cataloging Standards and Texts}

RDA, the new cataloging code intended to replace AngloAmerican Cataloguing Rules, 2nd ed. (AACR2), was under development throughout the period; drafts and discussion papers appeared on the website of the Joint Steering Committee (JSC) for Development of RDA, culminating in a full draft in November $2008 .^{31}$ While not yet finalized, RDA and its background and concepts were discussed in the cataloging literature. For example, in "Designating Materials: From 'Germane Terms' to Element Types," Weihs and Howarth traced the use of formalized terms following the title to designate physical format, to development of the general material designation (GMD), to RDA's proposed media type, carrier type, and content type.$^{32}$ In the context of the JSC's announcement that RDA would permit the use of family names as authors, Creider discussed the ways family names had been established in both the archival and cataloging traditions, and he also proposed changes to better address needs of users. ${ }^{33}$ In "Cataloging Cultural Objects (CCO), Resource Description and Access (RDA), and the Future of Metadata Content," Beacom identified commonalities and differences between RDA and CCO, a metadata scheme largely used in the museum community, and presented RDA's development as an opportunity for engagement between metadata communities, even when significant differences exist. ${ }^{34}$

"Resource Description and Access (RDA): Cataloging Rules for the 20th Century" proposed that the emerging code should focus more on moving library cataloging into the digital age. ${ }^{35}$ Rather than emphasizing continuity with the Anglo-American Cataloguing Rules in any of its manifestations, RDA developers should make a more radical break with the past, examine other metadata models-such as Dublin Core and CCO-and incorporate concepts regarding bibliographic relationships. "If new cataloging rules are developed without the parallel development of new models for library catalogs," authors Coyle and Hillmann warned, "then it will be necessary for some in the library world to set off in their own direction, rejecting what they see as insufficient change. ${ }^{" 36}$ Gorman, editor of AACR2, delivered an emphatic rebuke to RDA developers in "RDA: Imminent Debacle." Gorman's objections concerned the structure of the developing code, its relationship (or lack thereof) to ISBD, poor editing, and a perceived lack of compelling reasons for abandoning AACR2. He stated that "The RDA seeks to find a third way between standard cataloging ... on the one hand and the metadata crowd and boogie-woogie Google boys on the other. ... The sad thing is that betraying the former has not managed to appease the latter."37

As noted earlier, probably the most startling comments about RDA in the cataloging literature appeared in On the Record's recommendation 3.2.5: "Suspend Work on RDA." The LCWG advised the JSC to

suspend further new development work on RDA until a) the use and business cases for moving to RDA have been satisfactorily articulated, b) the presumed benefits of RDA have been convincingly demonstrated, and c) more, large-scale, comprehensive testing of FRBR as it relates to proposed provisions of RDA has been carried out against real cataloging data. ${ }^{38}$

The LC decided to proceed with the test of RDA, but the LCWG recommendation may have reflected unspoken feelings in the cataloging community. The literature of 2007-8 appeared to show more interest in and energy toward the topic of FRBR, one of the theoretical underpinnings of RDA, than around the new code itself. ${ }^{39}$ (FRBRrelated literature is discussed in the next section.)

The International Federation of Library Associations (IFLA) moved closer to a new Statement of International Cataloguing Principles to replace the statement known as the Paris Principles approved by the International Conference 
on Cataloguing Principles in $1961 .^{40}$ The Statement of International Cataloguing Principles, while not a cataloging code itself, was intended to update the Paris Principles, build on world cataloging traditions, and provide guidance for the development of future codes. Tillett provided a helpful overview of the April 2006 version of the draft statement at a 2006 IFLA Meeting of Experts, published in the meeting proceedings in $2007 .^{41} \mathrm{~A}$ final draft statement was available for worldwide review in 2008 (the final version was ultimately published in 2009). ${ }^{42}$

Also during this period, the IFLA issued International Standard Bibliographic Description (ISBD), Preliminary Consolidated Edition. Intended to supersede the individual ISBDs, the consolidated edition incorporated many revisions made during recent years to ISBD (A), ISBD (CR), and others, while retaining the basic ISBD structure and data elements. ${ }^{43}$

The third edition of Chan and Hodge's Cataloging and Classification: An Introduction (a staple of many cataloging departments) retained the organization and coverage of previous editions, but it expanded several topic areas and added coverage of metadata schema and other recent developments. ${ }^{44}$ Another worthy addition to the training shelf of libraries of many types (despite its title) was Standard Cataloging for Public and School Libraries, 4th ed., by Intner and Weihs. ${ }^{45}$ While including material especially valuable for school libraries (e.g., use of Sears List of Subject Headings), the work also provided cogent discussion and examples related to many cataloging topics and standard tools. Organizing Information from the Shelf to the Web, by Chowdhury and Chowdhury, also provided context to students and practitioners via an overview of library and nonlibrary approaches to organizing information. ${ }^{46}$ This work, with primarily British examples, covered cataloging rules and concepts (e.g., AACR2, the FRBR model), MARC formats, major library classification schemes (Colon Classification, LCC, Dewey Decimal Classification (DDC), Universal Decimal Classification), controlled vocabulary for subject description, and the structure of thesauri. It also discussed issues in organizing Internet resources, such as the application of vocabulary control tools.

\section{FRBR}

FRBR, a conceptual model of the bibliographic universe, continued to be a major focus of cataloging literature and made appearances in many publications of which FRBR was not the stated topic. ${ }^{47}$ Still, a decade after publication of the final report of the IFLA Study Group on Functional Requirements for Bibliographic Records, FRBR concepts remained difficult for many to grasp with confidence. FRBR: A Guide for the Perplexed, by Maxwell, came to their aid, demonstrating the entity-relationship model of FRBR and explaining FRBR entities, relationships, and user tasks in clear, accessible language. ${ }^{48}$ Maxwell also discussed difficulties in applying the entity-relationship model to existing databases of MARC records and the lack of progress, so far, in integrating FRBR concepts into catalogs and codes. A special section of the Bulletin of the American Society for Information Science and Technology presented FRBR concepts, their implications, and the challenges facing FRBR implementation in information systems. Riva, chair of the IFLA FRBR Review Group, provided a concise introduction for this section, with discussion of FRBR's influence on emerging cataloging codes and other ongoing developments involving authority records. ${ }^{49}$ Another helpful contribution was Dickey's "FRBRization of a Library Catalog: Better Collocation of Records, Leading to Enhanced Search, Retrieval, and Display. ${ }^{, 50}$ Dickey discussed the benefits of applying FRBR concepts to catalogs-showing advantages particularly for collections of resources in music and fine arts, theology, and literature - and described technical solutions for changing database structure to reflect bibliographic relationships.

Understanding FRBR: What It Is and How It Will Affect Our Retrieval Tools, edited by Taylor, contained essays on FRBR's principles and development, its relationship to cataloging history, and its possible applications in a number of library and other environments. ${ }^{51}$ For example, Shadle's "FRBR and Serials: One Serialist's Analysis" presented a view of how serial publications might be modeled in FRBR, and Vellucci's "FRBR and Music" discussed the FRBR structure as it related to musical works and expressions. "FRBR and Works of Art, Architecture, and Material Culture," by Baca and Clarke, demonstrated that for many cultural objects, "the conceptual model of the FRBR Group 1 entities (work, expression, manifestation, item) does not apply" because work is embodied in a single material object rather than existing as an abstract entity. ${ }^{53}$ In "Bibliographic Families and Superworks," Smiraglia distilled much of his thinking about works, constellations of works, and instantiation networks in the context of FRBR concepts of work, expression, and manifestation. ${ }^{54}$

The IFLA Working Group on Functional Requirements and Numbering of Authority Records (FRANAR) was appointed in 1999 to analyze FRBR entities related to authority data (e.g., persons, families, works, and places), their attributes, the names by which they are known, and controlled access points for them. FRANAR's draft report, discussing relationships that may exist between names of entities and access points based on those names, was available for review and comment on IFLA's website during the period under discussion. (When this review was written in mid-2009, however, the draft had been replaced on IFLA's site with publication information for FRANAR's Functional Requirements for Authority Data (FRSAD): A 
Conceptual Model..$^{55}$ Meanwhile, the IFLA Working Group on Functional Requirements for Subject Authority Records (FRSAR) posted a draft in November 2008, addressing its charge

- to build a conceptual model of Group 3 entities within the FRBR framework as they relate to the aboutness of works,

- to provide a clearly defined, structured frame of reference for relating the data that are recorded in subject authority records to the needs of the users of those records, and

- to assist in an assessment of the potential for international sharing and use of subject authority data both within the library sector and beyond. ${ }^{56}$

"Functional Requirements for Bibliographic Records: An Investigation of Two Prototypes" considered how the FRBR conceptual model worked when applied to two prototype bibliographic databases, LibraryLabs (National Library of Australia) and FictionFinder (OCLC). Search results pointed out some difficulties in implementing FRBR and issues that need resolution. ${ }^{57}$ "Perhaps the biggest drawback of FRBRised displays in the prototypes is that they give a sense of completeness, even though they don't allow users to carry out all of their tasks," observed authors Pisanski and Žumer. ${ }^{58}$ Nevertheless, they concluded, "even imperfect displays of the structure of the bibliographic universe should be better than the displays usually associated with OPACs, especially once the user understands the problems related to the concept." ${ }^{\text {"59 }}$

"Making the Pieces Fit: Little Women, Works, and the Pursuit of Quality" reported on research into the extent to which records for manifestations of an identified work set could be automatically identified, since problems in cataloging rules and practice have resulted in records that may make the automatic identification of work set members difficult. ${ }^{60}$ The project selected four works of fiction (one of which—Little Women — presented a particularly tricky situation) and used a detailed, multiple-pass process utilizing information in authority and bibliographic records as well as LCC numbers to identify work set members. For the four works, 77 to 95 percent of the records were, ultimately, correctly identified. Authors Carlyle, Ranger, and Summerlin proposed further research into the potential of records' LCC numbers as work identifiers, among other possibilities, and concluded that "by expanding the means by which author name and title attributes identifying a work are discovered, an automatic work identification process could work very well to improve catalog performance." ${ }^{\prime 61}$

Petek, in "Bibliographic Families and Relationships among Family Members in COBIB," used an entity-relationship model to examine the Slovenian national cooperative bibliographic database, COBIB ${ }^{62}$ The project constructed bibliographic "families" by identifying the progenitor (the work or superwork level in FRBR) and all the related "family members" (expressions and manifestations), and then analyzed the size of bibliographic families, types of relationships presented, and how well those relationships were expressed in the bibliographic records. While the catalog managed to identify family members, the work identification was only done implicitly. Based on how poorly family relationships were expressed in bibliographic records, Petek proposed an authority database for works, to which all related bibliographic records would be linked: "Since there is a difference between the content and the carrier, i.e., the work and the item, and assuming that users are more interested in works, some changes should be undertaken to adapt the current catalogue to new user needs."

Université catholique de Louvain in Belgium has been experimenting with FRBR cataloging since 2003 and is working on a FRBR approach for cataloging maps. In "FRBR: An Opportunity for Map Collections and Map Users?" Kalf described this work and presented theoretical examples for FRBR's use with maps, with this caveat: "One thing is clear: a serious theoretical approach must be developed prior to beginning any cataloguing to organize information and build a coherent FRBR tree., ${ }^{, 64}$ Kalf noted that maps have characteristics—-such as scale-that could be assigned either to the expression or manifestation level; she also enumerated other issues with map cataloging and FRBR and presented possible solutions.

"Linking Print and Electronic Books: One Approach" provided an example of how a library might use FRBR concepts to serve users more effectively. ${ }^{65}$ Having purchased table-of-contents information to enrich records for many print books, the library wished to alert users to the availability of electronic manifestations for the same titles, though the records for the electronics versions lacked the TOC information. This was accomplished by using a nonstandard, local system-specific field to link the parallel records for the two manifestations; users who retrieved one record were provided a link to the record for the other format. Authors Simpson, Lundgren, and Barr "encouraged others to explore creative solutions that will overcome the absence of data . . . that might have facilitated navigation among different versions, but which were not added to records for cost reasons in the past." ${ }^{\prime 66}$

\section{Cataloging Varied Resources}

Cataloging literature reflected the range of media, physical formats, and content carriers of current library resources. While Yee's Moving Image Cataloging: How to Create and How to Use A Moving Image Catalog covered several sets 
of pertinent data content standards, it focused most on the principles underlying effective systems for organizing information: "Instead of telling you how to do it right, this textbook will try to teach you how to think about it right." We recommend this bracing text to students, catalogers struggling with new media forms, practitioners with training responsibilities, and all those with an interest in continuing the role of human intervention in information organization. An operational contribution in this area of cataloging was Ho's report on one academic library's work to enhance bibliographic records for video recordings, for the benefit of OCLC and library users. ${ }^{68}$ Ho's article may, we hope, stimulate other libraries to engage in similar projects in the spirit of the LCWG's recommendations.

A welcome update to the 2002 version, Guide to Cataloging DVD and Blu-ray Discs Using AACR2r and MARC 21, issued by Online Audiovisual Catalogers (OLAC), addressed the treatment of Blu-ray discs and other recent questions in DVD cataloging. ${ }^{69}$ Each section, written by members of the OLAC DVD Cataloging Guide Update Task Force, provided guidance on using AACR2 and MARC 21 for DVDs of all kinds; included exemplars of packaging, labels, and on-screen credits; and showed how the information in those areas would be expressed in a MARC record. OLAC and the Music Library Association jointly produced the Guide to Cataloging Playaway Devices Based on AACR2 Chapters 6 and 9 to aid catalogers struggling to describe the integration of content and playback device. It also included examples with photos of the device showing the locations of bibliographic information and the corresponding MARC records. ${ }^{70}$

Descriptive Cataloging of Rare Materials (Books), the third version of a standard tool for treating rare printed monographs, added a chapter on objectives and principles and useful new appendixes on variations requiring the creation of new bibliographic records and collection- and corelevel records, among other topics. ${ }^{71} \mathrm{In}$ a change from earlier editions, the LC played a supporting role in the development of the publication while primary responsibility was undertaken by a committee of the Association of College and Research Libraries' Rare Books and Manuscripts Section. In "The Best of Both Worlds: Using CCO for Object Cataloging in Libraries and Special Collections," O'Keefe encouraged the use of the data content standard Cataloging Cultural Objects (CCO) where appropriate, identified data elements unique in either AACR2 or CCO, and provided advice about mapping between the two schemes. ${ }^{72}$

Allgood's ambitious "Serials and Multiple Versions, or The Inexorable Trend toward Work-Level Displays" examined the problems that multiple manifestations of serials continued to present to catalog users, and it analyzed current and possible solutions. ${ }^{73}$ Among the most promising solutions were catalog code revision and the application of
FRBR principles to catalog displays. Allgood's conclusion was applicable beyond the arcane territory of continuing resources cataloging:

It is time for librarians to determine if solutions to issues like the MulVer problem are complex because they have to be, or complex because librarians perpetuate practices that make them complex. . . . Within today's world of proliferating information carriers, providing consistent access to the content users seek is inherently complex, but to users it must appear simple. The job of today's librarians is to apply complex solutions to attain apparent simplicity — call it the Zen of librarianship. ${ }^{74}$

Latest versus successive entry cataloging of serial publications persisted as a topic of debate. In "Excessive Successive: Time for a Radical Change," Baia called for revising cataloging codes to allow latest entry cataloging. ${ }^{75}$ While acknowledging that introducing the concept of major and minor changes reduced the difficulties caused by successive entry practice, Baia noted that online journals-particularly those with all issues available in one place without regard to earlier titles under which issues may originally have been published-were not well served by successive entry cataloging; she proffered latest entry as a better fit with current technology. Grenci, on the other hand, considered arguments against successive entry but concluded that current technology could enable us "to bring together holdings from an entire run of serial records into one userfriendly catalog display." She advocated focusing efforts "on building and implementing online catalogs that make use of this potential." "In "Latest Entry Legacies: Confessions of a Guerrilla Cataloger," Randall recounted his experiences in a library that continued to use latest entry cataloging through the 1990s. ${ }^{77}$ While Randall believed the practice was beneficial for library users, the library ultimately discontinued latest entry treatment when it became "a hindrance because of its variance from international standards" and caused problems in synchronizing records with other libraries (including those within the same university), MARC tagging, and use of standard identifiers. ${ }^{78}$ Randall supported the development of sophisticated catalogs able to utilize linking data in the records: "If there is any solution to the problem of displaying the history of a serial in the catalog, I believe that it is in using encoded links between records to create a virtual record on the fly in response to a user's search in the catalog." from the Choice-of-Entry War," Shroyer presented results of informal opinion surveys of catalogers and public service librarians about latest or successive entry preferences. ${ }^{80}$ Both groups expressed a need and desire for catalogs to represent the history of a serial in a unified, composite display, 
with public service librarians finding "the general state of access information for serials unsatisfactory, if not abysmal, for users." "The manner in which many of the public services librarian respondents to my survey characterized the current organization and presentation of serials information in our catalogs should shake up catalogers and rule-making bodies," Shroyer concluded, and promoted changes in displays, linking practice, and serials cataloging rules. ${ }^{82}$

In "Catalog/Cataloging Changes and Web 2.0 Functionality," Kemp provided a useful summary of developments in cataloging standards, theory, and catalog display, with an eye to their effect on serials practice, and she explored the ways "changes in the catalog will be influenced by a new conception of the way users interact with the web, dubbed Web 2.0." ${ }^{83}$ Using five tasks, from finding an unknown journal article on a topic to finding a complete journal run, Kemp predicted how these changes would affect serials search and display in the online public access catalog (OPAC). "Now that we know what is possible, our challenge is to determine how libraries can partner with vendors, publishers, and users to create a maximally effective catalog for finding serials and any other information resource in the library's collection," she concluded. ${ }^{84}$

Collins' "Orphans Adopted Eighty-Nine Years After Conception" described the cataloging issues presented by updating loose-leaf publications-issues that tend to arise from their poor fit into the serials/monographs dichotomyand reviewed the history of their neglect in American cataloging codes, with an emphasis on recent developments. ${ }^{85}$ Collins concluded that with the 2002 revision of AACR2 chapter 12 and the corresponding changes to MARC 21, particularly the creation of the one-byte code "i" for integrating resources, cataloging practice at long last appropriately accommodated loose-leafs.

Fee's "Do You Have Any Ditko?: Comic Books, MARC, FRBR and Findability" used Tarango's "FRBR for Serials: Rounding the Square to Fit the Peg" and CONSER's "An Approach to Serials with FRBR in Mind" as starting points for applying the FRBR model to the treatment of comic books as serials, with sample records to illustrate the results. ${ }^{86}$ As Fee discussed, comic books present cataloging challenges because of their complex relationships between titles, questions of primary intellectual responsibility, and source-of-title issues, among other questions. Classification and subject treatment, including the use of genre terms, have often been locally defined, and the use of contents fields for analytic description also has presented problems. Fee proposed that despite the difficulties, better comics cataloging might promote format recognition as well as higher use.

Whether to allocate scarce resources to provide catalog access to free digital materials remained a vexing question for many libraries. To address the issue at their institution, Brown and Meagher tracked three years' use of carefully selected free digitized resources. ${ }^{87}$ They found that use statistics provided support for the value of adding URLs to catalog records. Harcourt, Wacker, and Wolley described Columbia University Libraries' approach to providing cata$\log$ records for free Internet resources, which involved selector input data, the use of an automated CGI program in Practical Extraction and Reporting Language (PERL) to harvest metadata, and access-level records. ${ }^{88}$

\section{Metadata and Cataloging in the Web World}

As libraries continued to move into a more varied information environment, catalogers continued moving into less familiar territory as well. Developments in metadata standards and practice, interoperability between schema, and applications to library service were among the topics discussed in the literature. Writing about the Semantic Web seemed to fall into two categories: how to harness Semantic Web applications to library metadata and processes, and how to integrate library metadata into the data harvesting and processing activities in the interoperable environment of the Semantic Web - both directions, of course, indicating that the world of bibliographic control had grown bigger than library cataloging.

Metadata, by Zeng and Qin, presented an overview of metadata standards and encoding schema, with background on general principles, records structure, quality measurement, and interoperability. ${ }^{89}$ Intended both as a textbook for students and a resource for practitioners, this work provided guidance in making informed decisions about metadata and digitizing projects.

Journal articles also provided introductory material. For example, Harpring presented a pithy introduction to $\mathrm{CCO}$ in "CCO Overview and Description." Whittaker described the salient points of Describing Archives: A Content Standard (DACS) and compared DACS with the developing RDA. ${ }^{91}$ Alexander's "Core Cataloging and Metadata Standards and Best Practices," a very useful and concise overview of metadata schema for science and technology materials, described several schema, including their applications and full documentation, as well as encoding schemes, interoperability, crosswalks, and opportunities for continuing education in this area. "Metadata for All: Descriptive Standards and Metadata Sharing Across Cultural Heritage Communities," by Elings and Waibel, explained key concepts for understanding metadata standards; briefly discussed the primary standards used by library, archive, museum, and visual resources communities; and proposed reconceptualizing standards as "material specific, not limited to one particular community." "What emerges," they concluded hopefully about the current metadata environment, "is not a picture of visual resources, libraries, archives 
and museums promulgating different standards to describe the same materials, but a rich toolset of descriptive practices that are uniquely adapted to the particular material type they have been originally designed to characterize."94

Using the Open Archives Initiative Protocol for Metadata Harvesting, by Cole and Foulonneau, described the process of conceiving, implementing, and maintaining an Open Archives Initiative (OAI)-compliant digital repository. ${ }^{95}$ This work defined the scope and purpose of OAI-PMH (Open Archives Initiative Protocol for Metadata Harvesting) and provided context for its use and development in the scholarly communications process. In addition to detailing this protocol's technical aspects, the work examined organizational issues in implementing digital library services with aggregated metadata. The authors noted that "facilitating the transport of metadata is not the same as facilitating the generation and use of metadata end to end in a digital library context. Metadata creation and use remain in large part a human-mediated process, and human factors affect the success of the process. ${ }^{\text {"96 }}$ Not unlike the LCWG, they reminded us that "users are looking for resources, not metadata." 97

In "Knitting the Semantic Web," a thematic double issue of Cataloging \& Classification Quarterly edited by Greenberg and Méndez, contributions were predominately (but not only) from information managers and information engineers. ${ }^{98}$ McCathieNevile and Méndez summarized the value of using Resource Description Framework (RDF) in library metadata to support "global and interoperable Web information processing." potential and theoretical uses of Semantic Web applications for controlled vocabulary, relator terms, authority files, and authority control in general, and suggested that applying these concepts to Semantic Web technology would provide better results for both human and machine. ${ }^{100}$ Greenberg also examined ways in which traditional library functions could be applied to the Semantic Web and drew parallels between circulation and digital resource use, collection development and document selection, cataloging standards and metadata standards, schema, and ontologies. ${ }^{101}$ Miles and Pérez-Agüera proposed that Simple Knowledge Organization System (SKOS)—a Semantic Web language currently in development for representing controlled, structured vocabularies - could be applied to resource collections that are part of the Semantic Web. ${ }^{102}$

"Framework for a Bibliographic Future," by Coyle and colleagues, proposed a metadata system with four layered components. ${ }^{103}$ These components consisted of an "abstract metadata model" as the foundational level, providing basic structures and relationships; a "domain model," defining structures and relationships in the domain or application the metadata addresses; guidance for creating or assigning values; and encoding, with the assumption that metadata might be encoded in different machine-readable formats while still being exchangeable. The draft document presented possibilities for a bibliographic description set based on Dublin Core Abstract Model, including some FRBR entities, and provided an example of a display.

Journal articles summarized successful metadata projects that other libraries could use as models. In "Integrating a Digital Library and a Traditional Library," Benedetti, Cody, and Hanerfeld described a project in which individual metadata records for digital objects created by faculty were harvested, crosswalked into MARC and Qualified Dublin Core, and migrated into the library's catalog and OCLC WorldCat. ${ }^{104}$ "An Operational Model for Library Metadata Maintenance," by LeBlanc and Kurth, presented a model for metadata maintenance loosely based on J. A. Zachman's descriptive framework for information systems architecture and drawing on the assumption that libraries can apply catalog maintenance skills to a broader information environment. ${ }^{105}$ Using their model, libraries can examine and create interdepartmental and interinstitutional metadata maintenance workflows beyond their MARC-based catalogs. "Moving Beyond MARC: Initiating and Embracing Change in a Traditional Technical Services Department," by Feltner-Reichert and Veve, described the process one department undertook to integrate metadata production resulting from a digitization project into its workflows, and the training, team-building, and workflow changes required to succeed. ${ }^{106}$

Brown and Harvey's "Adding Archival Finding Aids to the Library Catalogue: Simple Crosswalk or Data Traffic Jam?" reported on a project to convert Encoded Archival Description (EAD) finding aids for archival collections to MARC 21 for loading into the local catalog. ${ }^{107}$ While archivists generally reject MARC 21 as too limited for archival purposes, integrating finding aids into the catalog may increase their exposure; linking to the full finding aid mitigates limitations of MARC 21. Brown and Harvey described the crosswalk between EAD and MARC 21 (a relatively simple process with software like MARCEdit) and compared an EAD record with the postconversion MARC record. While no data was yet available to show whether the project actually increased discovery of archival collections, the authors believed their "experience suggests that the possibilities of joint library and archives cataloguing project are viable and reap benefits for both parties." 108

\section{Classification and Subject Access}

Thirty new editions of LCC schedules were issued during 2007-8, and several included significant changes and new features. ${ }^{109}$ For example, a number of law schedules included changes and simplifications made to form division 
tables; Arabic script and Chinese characters, in addition to equivalent Latin script, appeared in pertinent areas of several schedules. The 2007 edition of M, Music had a number of new features, from updated captions, more explanatory notes, and many classification numbers not previously published, to a greatly revised index with many more terms from LCSH. Interestingly, $E-F$, History of the Americas included a reinstatement: Its preface noted that the "lengthy histories that had originally appeared under the name of each U.S. state and Canadian province in the 1913 edition but were removed from subsequent editions, have been restored."110

New print editions of DDC were not issued during the biennium. However, the electronic versions of DDCWebDewey and Abridged WebDewey-were regularly updated to incorporate new numbers and index entries. In addition, the Dewey website (www.oclc.org/dewey/default .htm) provided mappings between new entries in LCSH and Dewey numbers. A new textbook in the use of DDC, Satijas The Theory and Practice of the Dewey Decimal Classification System, published in England and written by a library and information science (LIS) professor at Guru Nanak Dev University in India, was itself an indication of the international scope of DDC use. ${ }^{111}$ Satija emphasized the history, development, governance, and philosophy of DDC and perhaps included fewer exercises than might be found in a North American textbook on the subject; a reviewer in an Australian library journal praised the work's clarity and emphasis on concepts and made the suggestion of using it in conjunction with "a practical course on number synthesis and number building."

A revised edition of The Universal Decimal Classification: A Guide to Its Use, by McIlwaine, was published by the UDC Consortium in 2007. ${ }^{113}$ This edition did not represent a complete rewriting of the 2000 edition, but it did incorporate changes made through 2006 and presented updated examples. While the UDC is not used widely in North America, it continues to be popular internationally, and interest in its potential in automated applicationsfor example, as a mapping mechanism across domains or languages, or as a source of structured vocabulary-has grown in recent decades. In "Use of the Universal Decimal Classification: A World-Wide Survey," Slavic presented results of her study using e-mail interviews with LIS professionals in 208 countries, and a literature review. ${ }^{114}$ While the survey did not provide information about the number of institutions using UDC, results did show use in 124 countries (60 percent), with UDC the main classification system in 34 countries (28 percent) in Europe, Africa, and Asia. Slavic believed this was evidence that UDC remained "an international de facto standard in indexing."115

In an article in Knowledge Organization, Green identified a crucial paradox of classification systems: "Relationships are at the very heart of knowledge organization," but knowledge organization schemes do not necessarily express relationships well. ${ }^{116}$ After identifying the types of entity classes and relationships important in knowledge organization, Green discussed these classes and relationships in FRBR, bibliographic catalogs, DDC, and subject thesauri. She concluded, "Despite the centrality of relationships, their expression in knowledge organization schemes seldom rises to full and systematic expression." 117

While North American librarianship has focused on classification as a device for shelf organization, classification also can be used for identification and retrieval from catalogs and other databases. Bland and Stoffan described the development of a "classified browse" feature in the online public catalog of Western North Carolina Library Network (WNCLN). ${ }^{118}$ Extracting LC class numbers and associated subject headings, the system built a hierarchical classification display with descriptive captions to offer searchers an additional way of identifying pertinent resources.

Following the practices of bookstores, some libraries have abandoned the use of traditional library classification for shelf arrangement in favor of shelving by genre, general subject categories, and so on. "Finding What You're Looking For: A Reader-Centred Approach to the Classification of Adult Fiction in Public Libraries," by Maker, proposed a variation of genre arrangement based on the target reader market (e.g., literary fiction versus popular fiction). ${ }^{119}$ On the other hand, Brett's "Classification Practice in Law Libraries: A Brief Survey" found an increasing use of subject classification schemes in law libraries in the United Kingdom and Ireland. ${ }^{120}$ While Moys was the most frequently used scheme, many law libraries used classification schemes of their own devising. "The Making of a Classification Scheme for Libraries of Judaica" outlined the history, development, structure, and applications since the 1950s of A Classification System for Libraries of Judaica, from the point of view of one of its originators, David H. Elazar (brother of Daniel Elazar, the system's other author). ${ }^{121}$ The system was organized "according to Jewish concepts and based on Jewish thought and terminology," which enhanced its suitability for browsing special collections of Judaica. ${ }^{122}$ These articles demonstrated the wide divergence of classification practice that persists internationally and among different types of libraries, and even among libraries of the same type.

In "Thesauri and Facets and Tags, Oh My! A Look at Three Decades in Subject Analysis," Schwartz reviewed developments in this area from the 1970s to the present, observing that facet analysis tended to lead to "the systematic discovery and assembly of the syndetic and semantic structure- - the relationships intended to lead indexers and users around the vocabulary and promote match between query description and item description. ${ }^{.123}$ Unfortunately, the relationship structure has not been as well implemented in the 
online information setting as it has been in printed indexes or other tools. For example, in online catalogs, "relationships are typically displayed during search, but are neither clearly nor helpfully presented in most systems." ${ }^{\text {124 Schwartz }}$ considered thesauri, folksonomy, and guided navigation as areas in which researchers in subject analysis were responding to the new information environment. Folksonomy (or social, collaborative, or open tagging) provides the user some personal organization of known items; though specific and personal, folksonomy has a future as an augment to controlled vocabulary: "They are not mutually exclusive." 125 Facets in guided navigation, already implemented in Webbased commerce (a development that brought the work of Ranganathan to a wider audience, Schwartz noted), was beginning to show up in bibliographic catalogs.

"The Structure and Form of Folksonomy Tags: The Road to the Public Library Catalog," by Spiteri, examined a sampling of user-created tags from Delicious, Furl, and Technorati to determine how they matched with the National Information Standards Organization (NISO) standards for controlled vocabulary. ${ }^{126}$ Given the constraints of tagging conventions at the three sites (such as Delicious's requirement that tags not contain spaces), the sample indicated that in terms of the types of concepts, the use of nouns, the use of alphabetic characters and correct spelling, and the use of a single word to represent a single concept, the tags closely followed the NISO standards. In the use of homophones and other ambiguous terms, nouns in the singular, and abbreviations, however, the sample tags did not conform to the NISO standard. Spitari concluded with the suggestion that libraries that implement folksonomy creation should provide guidance to users in tag creation (particularly in the construction of multiterm tags), a link to reference works that would allow users to disambiguate homographs, instructions about using singular and plural forms of nouns, and an acceptable use policy. Peterson's "Parallel Systems: The Coexistence of Subject Cataloging and Folksonomy" briefly described catalogs that employed both controlled subject vocabulary and usersupplied subject tags—including Amazon, the University of Pennsylvania's PennTags, and the Montana State University electronic theses and dissertations database (ETD) - as well as projects that encouraged patrons to take data or records and reuse them in individual databases, and projects that encouraged users to contribute links and images to supplement the database. ${ }^{127}$ While social tagging may have potential for popularity, use statistics for PennTags and ETD were not yet high. Peterson concluded that "the question of whether library users look for the social interaction features of Web 2.0 in the databases where they conduct library research remains." 128

Tag clouds, used by tagging services and more formally known as weighted lists, have generated interest as retrieval mechanisms. "The Folksonomy Tag Cloud: When Is It Useful?" reported the results of an experiment in which researchers took a discrete amount of information, had study participants tag it, then set the participants specific information-seeking tasks using either a tag cloud or a search interface. ${ }^{129}$ Open-ended and nonspecific searches were successful using the tag cloud; the tag cloud was useful for browsing or as a starting point for searches because the visual summary could be used to familiarize a searcher with the information domain. On the other hand, specific information was retrieved more easily with the search interface. Authors Sinclair and Cardew-Hall made this interesting observation about user-created metadata: "Individuals ostensibly create tags to serve their own needs, and in doing so, a consensus vocabulary emerges." ${ }^{130}$ Should this consensus vocabulary become a controlled vocabulary? Noruzi's "Folksonomies: Why Do We Need Controlled Vocabulary?" an editorial in the online journal Webology, proposed that a folksonomy-based system should use a thesaurus. ${ }^{131}$ Reasons included the resolution of the singular-plural bugaboo, correction of typographical errors, use of preferred terms in the case of synonyms, and the consistency of depth or specificity of tagging, among other concepts familiar to library catalogers. Noruzi concluded:

Folksonomy-based systems can employ optional authority control of subject keywords, place, personal or corporate names and resource titles by connecting the system to established authority control files or controlled vocabularies using new techniques. A folksonomy-based system needs a controlled vocabulary and a suggestion-based system. . . . In the future, it should be possible for search engine designers to design folksonomy-based engines with controlled vocabularies in different fields to improve web information retrieval. ${ }^{132}$

"Measuring the Extent of the Synonym Problem in Full-Text Searching" reported on a study in which a sample of ninety single-word synonym pairs was searched for, singly and jointly, in the Yahoo! database. ${ }^{133}$ Authors Beall and Kafadar began their study using Google, but found they could not predict or explain significant discrepancies in the numbers of websites retrieved. Findings showed that the extent of the synonym problem depended on whether one searched the more common of the synonyms. As many as 30 percent of sites might be missed in the great majority of common word pairs; full retrieval required searching on synonyms. The authors believed "the data demonstrate the value of vocabulary control and cross references in providing more precise search results," and suggested their method could be used to establish a benchmark data set regarding specific search algorithms' abilities to minimize 
the synonym problem. ${ }^{134}$ As shown by this article, the possible applicability of approaches associated with traditional library cataloging - such as a system of cross references, whether seen or unseen by the searcher-to the broader universe of information control is clearly an area for further investigation and development.

\section{Questions of Diversity and Diverse Perspectives}

Many libraries in North America are evaluating and modifying services and collections to include and better reflect diverse ethnicities, peoples, and perspectives. The literature of cataloging and classification in 2007-8 contributed to these initiatives. While the contributions discussed in this section might easily be included under different categories, we have collected them here to draw attention to this developing area of the literature.

Not all the authors would agree with this separation, we suspect. As Christensen noted, a "minoritizing view" in bibliographic access tools draws attention to difference, while a "universalizing view . . c calls for unmarked representation, terminology and hierarchical structure that don't call attention to differences, emphasizing instead the unified whole." 135 Using Greenblatt's 1990 study on gay- and lesbian-related terms in LCSH as a starting point, Christensen's "Minoritization vs. Universalization: Lesbianism and Male Homosexuality in LCSH and LCC" examined gay- and lesbian-related terminology in LCC, as well as changes in LCSH during the last two decades. He concluded, "Keeping up with current connotations and usages of various terms won't ensure we please everyone, . . . but it will allow us to classify and describe concepts in a way consistent with current usage and with as much respect as possible to the various people these terms describe."136

In "Dewey Deracialized: A Critical Race-Theoretic Perspective," Furner introduced critical race theory as a framework for evaluating library classification schemes. Applying the theory to DDC and particularly to table 5 of DDC 21 and 22, Furner discussed both the historical significance and the results of changes in recent editions related to racial categories: With the changes, it became more difficult to find materials on topics related to racial categories, especially for racially mixed people. He observed, "We might consider that any decision taken to prevent classifiers and searchers from the use of racial categories is to ignore an everyday reality in which those categories are invoked not only in the distribution of social and political power, but also in individuals' self-identification." 137

"Subject Headings for Aboriginals: The Power of Naming" examined the weaknesses of LCC and LCSH for classifying and describing materials from Native American cultures in the United States and First Nations in Canada, and it described proposed solutions by Library and Archives Canada (LAC). ${ }^{138}$ A consultative process between the Working Group on Collection Policies at the National Library of Canada (now LAC) and aboriginal groups, continuing with an advisory group called Committee on Aboriginal Resources and Services, resulted both in the identification of problem areas and concerns and in specific recommendations. Author Kam briefly identified related initiatives in the United States and in New Zealand and Australia; discussed the use of more culturally appropriate classification systems, such as Brian Deer Classification (developed by one of the earliest First Nations librarians in Canada); and described other efforts to develop accurate representations of First Nations and Aboriginals in catalogs. She observed that

progress is being made towards more culturally sensitive language for subject headings to describe First Nations materials. This progress is largely the result of a consultative process which, although lengthy, will most likely be a critical element in its success. ... In essence, the existence of these revised terms will push the language boundaries of subject headings to accommodate different perspectives and worldviews leading to a richer and more dynamic reflection of societies and cultures. ${ }^{139}$

In "North American Indian Personal Names in National Bibliographies," an essay in the volume Radical Cataloging, Exner (Little Bear) identified the characteristics of North American Indian name forms and naming traditions throughout life, showed how these name forms need special attention in terms of cataloging and authority control practice developed for European names, and analyzed the treatment of a test set of 185 North American Indian names in the online catalogs of ten national libraries. ${ }^{140}$ His study revealed a lack of consistency that could be problematic for the international authority control movement. "Don't Class Me in Antiquities! Giving Voice to Native American Materials," also in this collection, presented a discussion between Webster and Doyle of issues related to cataloging and classifying these resources. ${ }^{141}$ Included was a list of examples of alternative thesauri and classification schemes from North America, Australia, and New Zealand, developed to help provide accurate and culturally appropriate cataloging for indigenous works.

Chapman addressed resource discovery in the catalog from the perspective of visually impaired individuals. ${ }^{142}$ Interestingly, in light of Bowman's history of annotations in cataloging (see "Cataloging History" below), Chapman advocated the inclusion of summaries or abstracts in catalog records for the visually impaired, since this population is 
likely to rely on the catalog entry rather than the dust jacket in making selections.

In 'Subject Access for Readers' Advisory Services: Their Impact on Contemporary Spanish Fiction in Selected Public Library Collections," Hall-Ellis considered questions related specifically to readers' advisory, but also more generally addressed how enhancing the catalog with Spanish subject headings could provide better access to the collections for Spanish-speaking patrons. ${ }^{143}$ Unfortunately, the study revealed that even for the five public library systems with significant Spanish-speaking populations under study, there was no consistent addition of subject headings in Spanish. "Therefore, delivering readers' advisory services to patrons who seek contemporary Spanish language adult fiction titles requires a reliance on independent knowledge on the part of the librarian or reader," while a catalog with Spanishlanguage headings might enable independent discovery by those without this level of knowledge. ${ }^{14}$

Strottman analyzed problems in the subject treatment of cultures and history in a specific region of the United States in "Some of Our Fifty Are Missing: Library of Congress Subject Headings for Southwestern Cultures and History." 145 To fill gaps in coverage, Strottman recommended the submission of new headings to the Subject Authority Cooperative Program (SACO) of the Program for Cooperative Cataloging (PCC); to correct misrepresentations and biased and inaccurate headings more systematically, she proposed establishing a SACO Southwest Funnel Group.

Jiang's "Lost in Translation: The Treatment of Chinese Classics in the Library of Congress Classification" showed that the group of ancient works known as the Chinese Classics (called jing in Chinese) has been misinterpreted and therefore misplaced in the LCC; Jiang recommended moving them from "Literature" to "Philosophy" for a more accurate treatment. ${ }^{146}$ Park used Korean examples to demonstrate issues in cross-language and cross-cultural access to names and subjects. Park observed that "natural language is not just mere arrangements of words, but the mirror of culture" and that the development of cross-lingual subject access schemes was "hindered by the lack of common conceptual mapping criteria that are interoperable across languages and culture."147 "The Colonial Bias: Library Classification in Aotearoa New Zealand," by Bednarek, described the difficulties Western cultural assumptions create for Maori patrons trying to locate library materials or even comprehend the role of the library as an institution. ${ }^{148}$ While most university libraries in Aotearoa New Zealand use LCC to classify their collections, Maori epistemology does not map well to the Western European epistemology that informs LCC.

"A Drum Speaks: A Partnership to Create a Digital Archive Based on Traditional Ojibwe Systems of Knowledge," by Powell, reflected on a project to catalog, preserve, and digitize objects created by the Ojibwe people of northern Minnesota. ${ }^{149}$ This article asked a number of complex and difficult questions for librarians and others involved in the digitizing project, among them the following:

- Does digital media inadvertently encode western epistemologies into the programming, design, and interface of Web-based learning environments?

- What would a digital archive ... look like if designed in close cooperation with respected members of Ojibwe communities?

- Is digital technology . . . better able to represent and integrate traditional "texts" - such as oral histories, beadwork, pictographs etched on birch bark, dance, drumming, and songs - than its predecessor, print culture? ?150 $^{2}$

Powell reported that the project attempted to utilize "Ojibwe language, stories, and knowledge to shape the tags, codes, and metadata that constitutes the digital architecture of the site," and that those involved in the project were

still struggling together to determine how this living system of knowledge can be translated into digital codes. We have begun to understand that stories should be more important than categories ... and we are all beginning to realize that the Ojibwe are the most qualified to create this new folksonomy, once the digital architecture has been put into place. ${ }^{151}$

Ultimately, the article raised questions about the usefulness or appropriateness of applying U.S. librarianship's codified structures to the intellectual work of native cultures and of attempts at culturally neutral and value-neutral descriptions and knowledge organization.

Providing further food for thought for subject catalogers was Olson's "How We Construct Subjects: A Feminist Analysis." 152 Olson explored possibilities for an alternative model of information organization that would emphasize "connected knowing" rather than hierarchical classification structures. She identified "four traces of connectednessassociative relationships, facets, FRBR, and [collaborative] tagging" already present in existing systems, and she proposed that FRBR, as an entity-relationship model, held further potential in this context, along with other possible approaches. ${ }^{153}$ Using Olson's suggestions to address the weaknesses in the expression of relationships in knowledge organization schemes, as observed by Green, and combining these insights with the insights gained in initiatives to include and reflect other worldviews, could result in new departures for knowledge organization and representation. ${ }^{154}$ 


\section{Other Reports of Practice and Research}

Acquiring new materials that have already been cataloged and processed is an appealing strategy for libraries facing staff reductions. "Shelf-Ready Books Using PromptCat and YBP: Issues to Consider," by Walker and Kulczak, analyzed results of their library's shelf-ready project and presented information useful to other libraries contemplating their own outsourcing contracts. ${ }^{155}$ The authors found that an individual review of each piece remained necessary to meet the library's quality standards (such as the presence of subject headings and the verification of URLs in 856 fields) or to conform to local library practice (such as locations based on size or classification practice for juvenile materials). While confirming that acquiring shelf-ready materials was a time-saver, the study also revealed that "accepting vendorsupplied records into our catalog without review would be to invite an unacceptable number of access errors." ${ }^{156}$

The use of MARC record services to provide records for individual electronic serials in dynamic databases is another strategy for maintaining complete catalog coverage with limited staff. "MARC Record Services: A Comparative Study of Library Practices and Perceptions," by Kemp, presented results of a survey of libraries using these services. ${ }^{157}$ While the majority of responding libraries used the separate-records approach, a significant number used some form of single-record treatment for titles in multiple formats and databases. Many libraries modified the records once they were loaded, and some found that brief records caused problems because of a lack of links to related titles. While respondents expressed general satisfaction with a service that provided access that might otherwise not be available, many respondents also indicated that record accuracy could be improved.

"A Survey of Local Library Cataloging Tool and Resource Utilization," by Miksa, reported on the use of specific cataloging and classification tools by staff in 103 public libraries in north Texas. ${ }^{158}$ Most of the libraries used an automated library system and performed their own cataloging (which mostly fell into the category of copy cataloging), and their overall use of standard cataloging documentation was low. Miksa also found "a disturbing lack of participation in the area of professional communication and the exchange of information" (e.g., subscriptions to electronic discussion lists or pertinent journals). ${ }^{159}$ Miksa used the results as a springboard to pose a number of questions about professional preparation for the future and "how well cataloging educators have prepared students to be catalogers." 160

Starting in spring 2005, the University of Michigan Library performed a comprehensive review of selection, acquisition, and cataloging workflow, prompted in part by migration to a new integrated library system and also by the library's partnership with Google "to digitize the entire University Library collection." "Catalog Information and
User Expectations in an Amazoogle World: Too Much? Too Little?" by Knott and colleagues described how one of the library's working groups gathered information about user needs and behavior as part of this review: a brief online survey intended to reveal users' impressions of their own catalog search behavior, and data from actual search logs. Results were combined to provide support for proposals to enhance records, preferably by automated means; to link print and electronic versions of resources; and to continue current levels of subject analysis, shelflisting for collocation purposes, and authority control, among other recommendations. Ultimately, the library made changes that read like a prequel to the LCWG recommendations: more staff dedicated to digital resources, more cataloging staff time devoted to work with unique print resources, more cataloging and processing outsourcing for widely held materials, and more enhancements to bibliographic records through automated techniques.

"VIAF (Virtual International Authority File): Linking the Deutsche Nationalbibliothek and Library of Congress Name Authority Files" described a project to create a virtual international authority file for personal names from the name authority files of two national libraries to demonstrate both the feasibility and benefits of linking authority records from different national files. ${ }^{162}$ Although some difficulties were encountered with the data, automated name matching algorithms were used to link 70 percent of names in common between the two files; linked bibliographic records were also used to enhance authority records to perform further matching and decrease the number of false matches. Authors Bennett and colleagues identified minor changes to authority records that could help with matching and increase the success of such a project in the future: "The long-term goal of the VIAF project is to combine the authoritative names from many national libraries and other significant sources into a shared global authority service."163

State and regional library journals may be an underappreciated source of brief articles of value to practitioners on aspects of cataloging operations. For example, "Showtime! Cataloging and Providing Access to Streaming Video Records in the Online Catalog," described issues encountered in cataloging these resources in a consortial environment. ${ }^{164}$ Authors McDonald and Johnston gave specifics and examples about the use of MARC fields, reaching consortial cataloging decisions, and authenticating users. "Online Cataloging Tools Versus Print Cataloging Tools," by Jin and Branton, presented the results of a survey of catalogers participating in the electronic discussion lists of four southeast U.S. associations. ${ }^{165}$ The authors concluded that online and print versions each had advantages for respondents; they suggested that designers of online tools, with their searching advantages, incorporate some features of the print tools. An unexpected survey result was the low number of recent MLS graduates who received training in the use 
of online tools, which may be an echo of Miksa's findings. ${ }^{166}$ "The Impact of the Library of Congress' Series Decision on LSU Libraries' Catalog: Minor Damage Now; Long-term Prospects Less Bright," by Nicholson, was one the few studies presenting data on the effects of the LC's 2006 decision to stop creating series authority records. ${ }^{167}$ While the study uncovered limited impact thus far, Nicholson anticipated that the long-term effects on authority control and retrieval might well be larger. He concluded "that the best response to the Library of Congress's decision is neither angst nor indifference, but rather a forward-looking resolve to assume greater responsibility for authority control in our libraries and for our cataloging in general." 168

\section{Catalogers: Education and Career}

Education to produce future catalogers who are prepared for the immediate conditions of employment while ready to lead the specialty into new environments continued to concern an aging profession, and was the topic of many journal articles. Citing posts on AUTOCAT as background, Elrod's opinion piece, "The Case for Cataloguing Education," lamented a perceived decline in the quality of cataloging and linked the decline to the lack of cataloging instruction in library and information science (LIS) education. ${ }^{169}$ Using the CONSER standard record (which may include corporate bodies and variant titles as access points without transcription or explanation in the record) and some RDA proposals as evidence, Elrod observed that "some library administrators and cataloguers engaged in rule revision and standard setting seem to lack a basis in the principles of cataloguing which should have been a part of their professional education." 170

Did the perception of a declining emphasis on education in cataloging match conditions "on the ground" in LIS education? In the second installment of his longitudinal study of cataloging education, Joudrey examined courses in organization of information (OI) in ALA-accredited graduate LIS schools in the United States and Canada. ${ }^{171} \mathrm{He}$ found that since 1998, there had been a 21 percent increase in the number of OI courses offered, though he reported that more than half of the courses included in the study fell "outside of what can be considered library cataloging courses," with metadata and organization courses likely to continue to grow in numbers. ${ }^{172}$ Joudrey posited that the biggest threat to the future of cataloging might be the lack of qualified cataloging instructors, and urged, "Catalogers, it is time to get that $\mathrm{PhD} .{ }^{.173}$

In 2007, the Committee on Education, Training, and Recruitment for Cataloging of the Association for Library Collections and Technical Services (ALCTS) sponsored an ALA preconference intended to address the disconnect between library employers and educators concerning the preparation of cataloging professionals. Titled "What They
Don't Teach in Library School: Competencies, Education and Employer Expectations for a Career in Cataloging," the event inspired the publication of a theme issue of the Journal of Education for Library and Information Science: "Making the Connection: Focusing on the Disconnect between LIS Education and Employer Expectations." The issue's lead article, "Educating Cataloging Professionals in a Changing Information Environment," identified core competencies for cataloging professionals, consistent with the goal of producing LIS graduates "with a solid background in information organization and technology and the flexibility and creativity employers expected." ${ }^{\text {174 }}$ Author Hsieh-Yee proposed a concerted effort by educators and practitioners to include the following goals: raise awareness and encourage appreciation of information organization in general and cataloging in particular, prepare students to be both catalogers and metadata specialists, and prepare new leaders in the cataloging area. While this article focused on cataloging education, it was of interest to all catalogers for its acknowledgement of conditions demonstrated or alluded to by many contributions to the literature of the biennium:

What has become apparent is that cataloging as currently practiced in most libraries and other information settings is not a cost-effective solution for managing digital resources. Nevertheless, the principles of cataloging and many concepts related to cataloging, such as authority control and controlled vocabulary, are extremely valuable for bringing order to the ever-expanding information universe. ${ }^{175}$

Practica present a means of balancing education in theoretical and applied aspects of bibliographic control. Damasco and McGurr surveyed entry-level catalogers, now working at member institutions of the Association of Research Libraries, who had participated in a practicum during their library school experience. ${ }^{176}$ They found that most of this group of catalogers agreed that a practicum should be a required part of the LIS curriculum because it augmented their classroom studies and provided a valuable means of learning the realities of work in a cataloging department.

"Employer Demands for Cataloger and Cataloger-Like Librarians and Implications for LIS" presented results of an exploratory study on employment in bibliographic control. ${ }^{177}$ To determine employer expectations for computer knowledge and skills, traditional cataloging knowledge, prior library experience, and other qualifications, author Lussky analyzed seventy-six ads for cataloging-oriented positions appearing in an online LIS joblist. Lussky found that both traditional cataloging knowledge and knowledge of newer technology standards were required by the majority of ads; the most frequently desired (as opposed to required) 
qualifications were familiarity with new technology tools, metadata schemes beyond MARC, and so on. Only 20 percent of jobs required a small amount of library experience. These findings should encourage LIS programs to incorporate practica into degree programs and to maintain curricula in traditional as well as emerging bibliographic control skills and standards. Zhu analyzed job advertisements for heads of cataloging in academic libraries. ${ }^{178}$ This study found-along with continuing core requirements and expectations concerning cataloging - some changes in job titles, responsibilities, and reporting lines, as well as growing expectations for knowledge of non-MARC metadata and digital resources: "The buzz word in the emerging titles was "metadata," she observed. ${ }^{179}$

Chapman analyzed job descriptions of metadata librarians in seven research libraries incorporating these positions into traditional technical services departments. ${ }^{180} \mathrm{He}$ identified their roles as collaboration, research, education, and development. He also discussed the benefits of assigning metadata responsibility to a professional librarian, noting that these roles "are descriptive of the responsibilities of professional, twenty-first-century librarians" generally. ${ }^{181} \mathrm{In}$ "Being a Librarian: Metadata and Metadata Specialists in the Twenty-First Century," Calhoun considered the changing roles of librarians - especially catalogers and metadata specialists-and the implications for metadata specialists of such trends as technology-driven research and teaching environments, disintermediation in information-seeking behavior, and the emergence of a global infosophere. ${ }^{182}$ Calhoun provided examples of effective knowledge management and twenty-first-century librarianship in a large research institution.

\section{Keeping Current: Columns and Blogs}

With many libraries experiencing hiring freezes, layoffs, and furloughs, practitioners were stretched to cover essential services - and many had little time and energy available to review research literature. In this context, thoughtful summaries presented in regular columns or series by outstanding contributors to the field provided valuable continuing education. Blogs by respected practitioners and researchers filled similar roles without the editorial oversight or intervention that can add value to the resource but with great immediacy.

The periodical Technicalities described itself as an "information forum for the technical services professional," and during 2007-8 it provided a significant service to practitioners through its well-selected array of columnists. Among the engaging discussions of issues in bibliographic control were McElfresh's "When a Journal Isn't a Journal: Patrons, Catalogs, and Monographic Series," an entry in her column "Serially Speaking." ${ }^{183}$ McElfresh recounted real-life difficulties her library's patrons experienced in accessing individual titles in these series and described a way that improved search properties of new online catalogs might be used to provide better access to these resources. Intner's "RDA: Progress or Problem?" an entry in her column "Dollars and Sense," clarified concerns about the developing successor to AACR2. ${ }^{184}$ In "Education for Librarianship in the Mid-20th Century, Part Two: Cataloguing, Classification, and Circulation," an article in her column "Interfaces," Weihs encouraged readers "to judge whether the fundamentals of librarianship have changed in the past fifty or sixty years and, if so, how great or how little the changes have been."185

Donlan's "Nexus: Where Reference and Technical Services Meet," a regular column in The Reference Librarian, provided useful approaches for communicating with colleagues in public services. For example, "An Unfortunate Event for Series, or, LC Outsourced You Back" showed the possible impact of the LC's controversial decision in answering reference queries. ${ }^{186}$ Adamich's regular contributions to Knowledge Quest covered topics related to cataloging in school libraries, from CE-MARC to FRBR. "RDA (Resource Description and Access): The New Way to Say 'AACR2," briefly examined the development and characteristics of RDA and stressed the connection between RDA and FRBR ${ }^{187}$ It could serve as an introduction to RDA for staff in many types of libraries, not just those serving K-12 institutions. In his column in The Unabashed Librarian, Berman continued his efforts to update and improve LCSH practice. His "One Book, Many Missed Opportunities; or, Why Cataloging Matters (When It's Done Right)" demonstrated how more useful and complete access might have been provided for Bliss Broyard's One Drop: My Father's Hidden Life, a Story of Race and Family Secrets. ${ }^{188}$ Berman concluded with an "adage for critical catalogers: No matter who cataloged it first, try to make it better. (You usually can.)"189

Blogs have two major functions: delivering news and announcements, often with much cross-linking to other blogs, and providing an unfiltered podium-the Internet's version of Hyde Park's Speakers' Corner. While many cataloging-related blogs of the biennium seemed to fall into the news-and-linking category and thus outside the scope of this essay, other blogs provided opinion pieces, professional musings, and personal essays. Dempsey's Weblog on Libraries, Services and Networks (http://orweblog.oclc .org) covered emerging bibliographic control and metadata practices, library service to "network people," and the application of Web 2.0 concepts to the library environment, as seen by a prominent member of the library profession, and was followed with interest - if not always agreement-by many catalogers. The blog 025.431: The Dewey Blog (http:// ddc.typepad.com/025431) provided practical advice for the use of DDC, particularly for emerging topics and current events. More personally, Burke, in "The Grim Outlook for 
Cataloging," an August 16, 2008, posting on Brigid's Blog, observed that "there is a lot of talk these days about the "future of cataloging" and expressed the view that "the future of cataloging looks bleak and confusing. We have a new set of standards and tools being put in place that don't seem very revolutionary, and yet the hype says they are." ${ }^{\prime 190}$

\section{Cataloging History}

Periods of intense change can prompt consideration of the past as well as the future, and the literature of this biennium included many treatments of historical topics, from cataloging as part of the history of information management, to development of current practices and standards, to memoir and biography. We began this review with literature speculating on cataloging's future, and we end it with literature reflecting upon its past.

Aiming to "resist the tug of mystical techno-futurism and approach the story of the information age by looking squarely backward," Glut: Mastering Information through the Ages, by information architect Wright, surveyed the entire history of human information management and technologies. ${ }^{191}$ While libraries and their organization made many appearances in Glut, one chapter, "The Industrial Library," about the development of library cataloging and classification, was particularly enlightening reading for catalogers, who do not often see Panizzi, Cutter, Dewey, Otlet, and Ranganathan presented within a much larger context. Indeed, Glut provided much surprising and useful background to ordinary day-laborers in information organization. And who knew that Cutter once wrote a futuristic essay about libraries in the late twentieth century in which there would be networked telegraphic access to library collections connected by a "fonographic foil"? 192

"Boston Library Catalogues, 1850-1875: Female Labor and Technological Change," by Mitchell, presented cataloging history in the context of two related themes: women's employment history and the development of office organization and technology. ${ }^{193}$ In the mid-nineteenth century, the Boston-Cambridge area had four large libraries with growing collections that needed cataloging. Starting in the 1850s, each of the four libraries began hiring women for this work. The women entering previously all-male library workplaces were mostly educated, described as assistants or clerks, and paid considerably less than their male counterparts. Most were unmarried, but not all (Sarah Appleton continued to work as a library assistant after marrying Charles A. Cutter, for example). Mitchell concluded that "libraries played an important role in the development of the female clerical workforce, and in Boston and Cambridge, it was seminal." 194 Library cataloging, for good or ill, thus influenced the creation of the female office worker. Praising the card catalog as a "system of record management . . . so fundamental that it can be considered a prototypical form of technology," Mitchell proposed that

the rise of the card catalogue, and the concomitant entrance of female clerical workers into increasingly bureaucraticized [sic] libraries, was a pivotal point not only in the history of libraries. The great library catalogues ... were catalysts for an extraordinary moment of institutional growth and change. ${ }^{195}$

The evolution of cataloging rules and best practices has, historically, occurred in part within professional library organizations. Commemorating the Past, Celebrating the Present, Creating the Future: Papers in Observance of the 50th Anniversary of the Association for Library Collections and Technical Services presented essays documenting both the history of ALCTS (formerly Resources and Technical Services Division, RTSD), the U.S. cataloging community's organizational "home" within the ALA, and some key developments in ALCTS specialties, including cataloging. Included were reminiscences of RTSD/ALCTS presidents, among them notable contributors to bibliographic control such as Ruth C. Carter, Robert Holley, Janet Swan Hill, Sheila S. Intner, and Michael Gorman. ${ }^{196}$ In "The True History of AACR2, 1968-1988: A Personal Memoir, by One Who Was There," Gorman, editor of AACR2, described the code's development in the context of earlier codes and emerging international standards, and he recounted his own role in creating AACR2 right down to the music he listened to while writing the draft in longhand ("the Eagles, Linda Ronstadt, etc."). ${ }^{197}$ In addition to this personal view of recent descriptive cataloging history, Gorman proffered the opinion that AACR2, rather than RDA, was the true break with the past, and that, with modifications, AACR2 could still be used as the basis of international and national codes. "Others," he noted, "think differently."198 In a related commemorative work, "Fifty Years of Library Resources b Technical Services," Connell performed a content analysis of articles appearing in this journal from 1957 to $2006 .{ }^{199}$ She found that the first thirty years of the journal's contents concentrated strongly on cataloging topics, but the focus had more recently been shifting: "Cataloging and classification articles still make up the majority on [sic] the content, but the proportion is decreasing." ${ }^{.200}$ In addition to national professional organizations, members of the cataloging community have historically been active in regional associations. An interesting contribution by Clemons and Goldberg, "Ohio Valley Group of Technical Services Librarians: A History," documented the history of this group from its formation as the Ohio Valley Regional Group of Catalogers in 1924 to the present. ${ }^{201}$ During the 1950s, the group's scope expanded into other library technical services; during the 2000s, topics in bibliographic control expanded to include FRBR, XML, 
and metadata schemes.

"Cartographic Materials: A Century of Cataloging at Library of Congress and Beyond," by Mangan, traced the history of map cataloging at the LC during the twentieth century and the concurrent development of cataloging treatment of these resources. ${ }^{202}$ Among the topics considered were recurring disputes about rules for the primary access point (e.g., by geographic area or by creator or issuing corporate body); the rejection by LC catalogers of the initial atlas schedule in LC class $\mathrm{G}$ and the later cooperative development and acceptance of an LC schedule for both maps and atlases; the development and implementation of MARC for maps; the ups and downs of cataloging rule development; and the effect of digital spatial data on cartographic materials cataloging. "The history of map cataloging history clearly illustrates the problems of having nonspecialists making decisions dealing with the organization, description, and classification of cartographic materials," Mangan believed. ${ }^{203}$ This review of the difficulties of a distinct resources community within library cataloging may be instructive as we attempt to establish collaborative relationships with other communities of practice.

H. E. Bliss (1870-1955) was the creator of the Bliss or Bibliographic Classification scheme and arguably "the first person to attempt a comprehensive and formal statement of the theory of classification." ${ }^{204}$ Broughton's elegant "Henry Evelyn Bliss: The Other Immortal, or a Prophet Without Honour?" examined the broader context of Bliss's philosophy of classification, the main features of his work, the originality of his contributions, and the extent to which many of his principles have been fully absorbed into modern classification and indexing theory - and, hence, are often not attributed to him. Of particular interest were discussions concerning a precursor to the concept of citation order in Bliss's work, his placement of classification within a social context and the resonance of this concept with contemporary theories of social classification or folksonomy, and his contributions to the development of facet structure. Also intriguing were speculations about recent developments in search engines that suggest "the classificatory approach is now regarded as more valuable than it may have been in the early days of digital resource discovery."205 Broughton concluded that "Bliss stands shoulder to shoulder with Ranganathan in terms of intellect and influence."206

"Women in Australian Librarianship: The Example of Jean Fleming Arnot," by McLeod, analyzed the career of Arnot (1903-95), a prominent cataloger and an activist for equal pay for women. ${ }^{207}$ The article focused on her working life from the perspective of her experience of "an intellectual and creative task - the art of cataloguing — at which Arnot excelled," and posited "a link between her professional identity and research skills and her contribution to the women's movement. ${ }^{3208}$ This is a starkly different perspective from the more usual view of women catalogers historically contributing to "an atmosphere of genteel propriety" and confined "to largely manual skills of copying and filing."209

Cataloger, Editor, and Scholar: Essays in Honor of Ruth C. Carter, edited by Holley, honored Carter's varied career with contributions in many areas of cataloging and classification, including a number of essays on historical topics. Of particular note was Bowman's “Annotation: A Lost Art in Cataloging," which described the rise and decline of annotations in cataloging and suggested that new forms of annotation, appropriate for the digital environment, might reemerge. ${ }^{210}$ For cataloging historians of the future, the volume included several articles related to Carter's own contributions, including an interview with Carter by Ewbank, a biographical essay by Henderson, and "Cataloging \& Classification Quarterly, 1990-2006," by Roe, Culberston, and Jizba, an analysis of the contents of that journal, an important producer of cataloging literature, during Carter's tenure as editor. ${ }^{211}$

\section{Conclusion: Cataloging Literature 2009-10 and Beyond?}

This review demonstrates, we believe, the vast extent of the literature of cataloging and classification during 2007-8, its international nature, diverse methods and approaches, varied authorship, expanding concerns, and, especially, its vitality. For example, the literature referring to the concepts of FRBR revealed great energy: eagerness to understand FRBR's possibilities, expand FRBR's scope, explain its value to others in the library and information communities, and develop varied applications that used FRBR concepts to create links and displays promoting more successful search and retrieval by users. Further opportunities for research include the development of additional strategies for identifying work sets and the comparison of observed search and selection by users in "FRBR-ized" catalogs versus traditional OPACs. As additional implementations of FRBR concepts develop, additional research questions will surface. For example, is the application of FRBR concepts more helpful to some categories of users or to users in some information environments, or when applied to some types of manifestations of works (e.g., editions of nineteenthcentury novels) as opposed to other categories of manifestations (e.g., successive editions of works in which currency is critical)? FRBR concepts and their possible uses or limitations are likely to inspire the research and publication of cataloging literature in the current biennium, as they did in 2007-8.

Other areas of innovative practice, research, and development should offer abundant opportunities to contribute to the literature as well. One need only look at the flurry of 
operational research and commentary resulting from the implementation of AACR2 to anticipate that testing and implementation (or not) of RDA will present rich fields for exploration. The globalization and internationalization of library information sources and applications will require attention to issues of transporting data across languages, character sets, and cultures. The development of metadata standards appropriate for specific cultures and peoples-by those peoples - and questions concerning the desirability or even possibility of creating a culture-neutral metadata standard also are important areas for examination. Projects and research that evaluate the application of some library cataloging approaches to nonlibrary and non-MARC environments could contribute to the larger universe of information access. While library uses of non-MARC metadata are proliferating, we believe the field needs to define underlying principles for optimizing the use of metadata originating in multiple sources and in multiple formats, thereby preventing the user from having lowest-common-denominator access. These topics are among those suggested by recent literature.

Several of the recommendations of the LCWG concerned the development of a culture of research and evaluation regarding issues in bibliographic control to create a stronger evidence base. We anticipate that cataloging and classification literature of the current biennium will be as extensive and vigorous as in 2007-8. With all the talk of the "end of cataloging," is this burst of productivity the flowering before the tree dies?

The answer, we believe, will not be solely determined by catalogers and researchers in bibliographic control, but will also emerge from the developing information environment and from libraries' decisions about their roles and how to fulfill them. It is clear that library cataloging will not be the only tree in the bibliographic forest. Nevertheless, considering the richness of much cataloging data, the adaptability of the profession in finding new ways to use this data, and the energy surrounding concepts such as FRBR and questions of diversity, we speculate that library cataloging and its literature will continue to develop and make distinctive contributions to the universe of information control.

\section{References and Notes}

1. Why the approximate numbers? We attempted to remove any remaining duplicates and reviews, but this often proved difficult before we connected to the resources themselves. Downloaded citations from sources contained varying amounts of information and made the firm identification of content difficult.

2. Association of College and Research Libraries Rare Books and Manuscripts Section Bibliographic Standards Committee, (ACRL RBMS BSC) and Library of Congress Cataloging Policy and Support Office (LC CPSO), Descriptive Cataloging of Rare Materials (Books) (Washington, D.C.: Cataloging Distribution Service, Library of Congress, 2007).

2. On the Record: Report of the Library of Congress Working Group on the Future of Bibliographic Control (Washington, D.C.: Library of Congress, 2008).

3. Ibid

4. Ibid., 4.

5. See, for example, Jeannette Ho, "Enhancing and Upgrading Records for Video Recordings in OCLC's WorldCat Database: One Participant's Experience at Texas A\&M University," Cataloging \& Classification Quarterly 46, no. 3 (2008): 238-68.

6. On the Record:, 34 .

7. Janet Swan Hill, "Entering an Alternate Universe: Some Consequences of Implementing Recommendations of the Library of Congress Working Group on the Future of Bibliographic Control," Library Resources \& Technical Services 52, no. 4 (Oct. 2008): 218.

8. On the Record, 2.

9. Ibid., 29.

10. Diane I. Hillmann, "Comments on Report of the Library of Congress Working Group on the Future of Bibliographic Control," http://docs.google.com/ View?docid=dn8z3gs_51dsqc77 (accessed Dec. 12, 2007).

11. Elaine Sanchez, Emerging Issues in Academic Library Cataloging \& Technical Services (New York: Primary Research Group, 2007): 132.

12. Library of Congress and Cataloging in Publication Division, CIP Poised for Change: Survey Findings and Recommendations of the 2006 CIP Review Group (Washington, D.C: Library of Congress, Cataloging in Publication Division, 2007).

13. Ibid., 94; On the Record, 15.

14. David Bade, "Structures, Standards, and the People Who Make Them Meaningful," in Responsible Librarianship: Library Policies for Unreliable Systems (Duluth, Minn.: Library Juice Press, 2007): 115-35.

15. Ibid., 127.

16. Martha M. Yee, "Will the Response of the Library Profession to the Internet be Self-Immolation?" Unabashed Librarian no. 144 (2007): 3.

17. Thomas Mann, “'On the Record’ But Off the Track: A Review of the Report of the Library of Congress Working Group on The Future of Bibliographic Control, With a Further Examination of Library of Congress Cataloging Tendencies," www.guild2910.org/WorkingGrpResponse2008.pdf (accessed Aug. 15, 2008).

18. David Banush and Jim LeBlanc, "Utility, Library Priorities, and Cataloging Policies," Library Collections, Acquisitions \& Technical Services 31, no. 2 (2007): 99.

19. Deanna Marcum, "The Future of Cataloging: Address to the EBSCO Leadership Seminar, Boston, Massachusetts, January 16, 2005," www.loc.gov/library reports/CatalogingSpeech.pdf (accessed Sept. 4, 2009), quoted in Banush and LeBlanc, "Utility," 101.

20. Banush and LeBlanc, "Utility," 101, 103.

21. Ibid., 107. 
22. Jeffrey Garrett, "Subject Headings in Full-Text Environments: The ECCO Experiment," College \& Research Libraries 68, no. 1 (Jan. 2007): 69-81. Garrett quotes from Deanna Marcum, "The Future of Cataloging," Library Resources \& Technical Services 50, no. 1 (2006): 5.

23. Garrett, "Subject Headings," 75.

24. Sheila Bair and Sharon Carlson, "Where Keywords Fail: Using Metadata to Facilitate Digital Humanities Scholarship," Journal of Library Metadata 8, no. 3 (2008): 249-62.

25. Ibid., 259-60.

26. Karen Markey, "The Online Library Catalog: Paradise Lost and Paradise Regained?” D-Lib Magazine 13, no. 1/2 (2007), www.dlib.org/dlib/january07/markey/01markey.html(accessed Apr. 25, 2008).

27. Ibid.

28. Ibid.

29. Tina Gross, "Who Moved My Pinakes?" in Radical Cataloging: Essays from the Front, ed. K. R. Roberto (Jefferson, N.C.: McFarland, 2008): 146.

30. Joint Steering Committee for Development of RDA, RDA: Resource Description and Access: Full Draft of RDA, www .rda-jsc.org/rdafulldraft.html (accessed Aug. 13, 2009); Anglo-American Cataloguing Rules, 2nd ed., 1988 revision (AACR2R) (Chicago: ALA, 1988).

31. Jean Weihs and Lynne C. Howarth, "Designating Materials: From "Germane Terms" to Element Types," Cataloging \& Classification Quarterly 45, no. 4 (2008): 3-24.

32. Laurence S. Creider, "Family Names and the Cataloger," Library Resources \& Technical Services 51, no. 4 (Oct. 2007): 254-62.

33. Matthew Beacom, "Cataloging Cultural Objects (CCO), Resource Description and Access (RDA), and the Future of Metadata Content," Visual Resources Association Bulletin 34, no. 1 (Spring 2007): 81-85.

34. Karen Coyle and Diane I. Hillmann, "Resource Description and Access (RDA): Cataloging Rules for the 20th Century," D-Lib Magazine 13, no. 1/2 (2007), www.dlib.org/dlib/january07/ coyle/01coyle.html (accessed Apr. 25, 2008).

35. Ibid.

37. Michael Gorman, "RDA: Imminent Debacle," American Libraries 38, no. 11 (Dec. 2007): 65.

38. On the Record, 29.

39. IFLA Study Group on the Functional Requirements for Bibliographic Records and International Federation of Library Associations and Institutions Section on Cataloguing Standing Committee, Functional Requirements for Bibliographic Records: Final Report, UBCIM Publications-New Series, vol. 19 (Munich: K.G. Saur, 1998), www.ifla.org/files/cataloguing/ frbr/frbr.pdf (accessed Mar. 1, 2010).

40. International Conference on Cataloguing Principles (Paris: 1961). Report. (London: International Federation of Library Associations, 1963): 91-96.

41. Barbara B. Tillett, "Draft Statement of International Cataloguing Principles: Overview," in IFLA Cataloguing Principles: Steps Towards an International Cataloguing Code, 4: Report from the 4th IFLA Meeting of Experts on an International Cataloguing Code, Seoul, Korea, 2006, ed. Barbara B. Tillett, Jaesun Lee, and Ana Lupe Cristán (Munich: K.G. Saur, 2007): 291-308.
42. IFLA Cataloguing Section and IFLA Meetings of Experts on an International Cataloguing Code, Statement of International Cataloguing Principles, www.ifla.org/en/publications/ statement-of-international-cataloguing-principles (accessed Sept. 17, 2009).

43. International Federation of Library Associations and Institutions ISBD Review Group and International Federation of Library Associations and Institutions Cataloguing Section Standing Committee, International Standard Bibliographic Description (ISBD) (Munich: K.G. Saur, 2007).

44. Lois Mai Chan and Theodora Hodges, Cataloging and Classification: An Introduction (Lanham, Md.: Scarecrow, 2007).

45. Sheila S. Intner and Jean Riddle Weihs, Standard Cataloging for School and Public Libraries, 4th ed. (Westport, Conn: Libraries Unlimited, 2007).

46. G. G. Chowdhury and Sudatta Chowdhury, Organizing Information: From the Shelf to the Web (London: Facet, 2007).

47. Functional Requirements for Bibliographic Records Final Report.

48. Robert L. Maxwell, FRBR: A Guide for the Perplexed (Chicago: ALA, 2008).

49. Pat Riva, "Introducing the "Functional Requirements for Bibliographic Records' and Related IFLA Developments," Bulletin of the American Society for Information Science and Technology 33, no. 6 (Aug./Sept. 2007): 7-11.

50. Timothy J. Dickey, "FRBRization of a Library Catalog: Better Collocation of Records, Leading to Enhanced Search, Retrieval, and Display," Information Technology \& Libraries 27, no. 1 (Mar. 2008): 23-32.

51. Arlene G. Taylor, ed., Understanding FRBR: What It Is and How It Will Affect Our Retrieval Tools (Westport, Conn: Libraries Unlimited, 2007).

52. Steven C. Shadle, "FRBR and Serials: One Serialist's Analysis," in Taylor, Understanding FRBR, 153-74; Sherry Vellucci, "FRBR and Music," in Ibid., 131-51.

53. Murtha Baca and Sherman Clarke, "FRBR and Works of Art, Architecture, and Material Culture," in Taylor, Understanding FRBR, 103

54. Richard Smiraglia, "Bibliographic Families and Superworks," in Taylor, Understanding FRBR, 73-86.

55. Glenn E. Patton and IFLA Working Group on Functional Requirements and Numbering of Authority Records, Functional Requirements for Authority Data: A Conceptual Model (Munich: K.G. Saur, 2009).

56. IFLA Working Group on Functional Requirements for Subject Authority Records, Functional Requirements for Subject Authority Data (FRSAD): Conceptual Model, 2nd Draft (June 10, 2009), nkos.slis.kent.edu/FRSAR/report090623.pdf (accessed Sept. 19, 2009): 7.

57. Jan Pisanski and Maja Žumer, "Functional Requirements for Bibliographic Records: An Investigation of Two Prototypes," Program: Electronic Library \& Information Systems 41, no. 4 (2007): 400-417.

58. Ibid., 416.

59. Ibid

60. Allyson Carlyle, Sara Ranger, and Joel Summerlin, "Making the Pieces Fit: Little Women, Works, and the Pursuit of 
Quality," Cataloging \& Classification Quarterly 46, no. 1 (2008): 35-63.

61. Ibid., 61.

62. Marija Petek, "Bibliographic Families and Relationships among Family Members in COBIB," OCLC Systems \& Services 24, no. 2 (2008): 91-100.

63. Ibid., 98 .

64. Ruth Kalf, "FRBR: An Opportunity for Map Collections and Map Users?" Liber Quarterly: The Journal of European Research Libraries 18, no. 2 (Sept. 2008): 280.

65. Betsy Simpson, Jimmie Lundgren, and Tatiana Barr, "Linking Print and Electronic Books: One Approach," Library Resources \& Technical Services 51, no. 2 (Apr. 2007): 146-52.

66. Ibid., 150.

67. Martha M. Yee, Moving Image Cataloging: How to Create and How to Use a Moving Image Catalog (Westport, Conn: Libraries Unlimited, 2007): xiii.

68. Ho, "Enhancing and Upgrading Records."

69. DVD Cataloging Guide Update Task Force, Cataloging Policy Committee, Online Audiovisual Catalogers, Guide to Cataloging DVD and Blu-ray Discs Using AACR2r and MARC 21, 2008 Update, www.olacinc.org/drupal/capc_files/ DVD_guide_final.pdf (accessed Dec. 12, 2009).

70. Playaway Cataloging Joint Task Force: Online Audiovisual Catalogers Cataloging Policy Committee, Music Library Association Subcommittee on Descriptive Cataloging, Guide to Cataloging Playaway Devices Based on AACR2 Chapters 6 and 9, (last updated Aug. 21, 2008), www.olacinc.org/drupal/ capc_files/playawaysPDF.pdf (accessed May 4, 2009).

71. ACRL RBMS BSC and PL CPSO, Descriptive Cataloging of Rare Materials (Books).

72. Elizabeth O'Keefe, "The Best of Both Worlds: Using CCO for Object Cataloging in Libraries and Special Collections," Visual Resources Association Bulletin 34, no. 1 (Spring 2007): 86-96.

73. Julian Everett Allgood, "Serials and Multiple Versions, or the Inexorable Trend toward Work-Level Displays," Library Resources \& Technical Services 51, no. 3 (July 2007): 16078.

74. Ibid., 175 .

75. Wendy Baia, "Excessive Successive: Time for a Radical Change,” The Serials Librarian 53, no. 1 (2007): 57-80.

76. Mary Grenci, "How Successive Entry Cataloging Stacks Up in Today's World," The Serials Librarian 53, no. 1/2 (2007): 97.

77. Kevin M. Randall, "Latest Entry Legacies: Confessions of a Guerrilla Cataloger," The Serials Librarian 53, no. 1/2 (2007): 81-91.

78. Ibid., 86 .

79. Ibid., 90 .

80. Andrew D. Shroyer, "Confessions of a Correspondent from the Choice-of-Entry War: Review of Responses to a Set of Informal Opinion Surveys," The Serials Librarian 53, no. 1 (2007): 99-123.

81. Ibid., 116.

82. Ibid., 118.

83. Rebecca Kemp, "Catalog/Cataloging Changes and Web 2.0 Functionality: New Directions for Serials," The Serials Librarian 53, no. 4 (2008): 99.

84. Ibid., 109.
85. Carol Morgan Collins, "Orphans Adopted Eighty-Nine Years After Conception, Or, Cataloging Updating Loose-Leaf Publications," The Serials Librarian 55, no. 4 (2008): 598614.

86. William T. Fee, "Do You Have Any Ditko?: Comic Books, MARC, FRBR and Findability," Serials Review 34, no. 3 (2008): 175-89; Adolfo Tarango, "FRBR for Serials: Rounding the Square to Fit the Peg," presented at the Operations Meeting, Apr. 24, 2008, www.loc.gov/acq/conser/FRBR-for -serials.pdf (accessed June 10, 2009); CONSER Task Force on Universal Holdings, "An Approach to Serials with FRBR in Mind," draft, rev. Diane Hillmann, Jan. 24, 2004, www.lib .unc.edu/cat/mfh/serials_approach_frbr.pdf (accessed June 10, 2009).

87. Christopher C. Brown and Elizabeth S. Meagher, "Cataloging Free E-Resources: Is It Worth the Investment?” Interlending \& Document Supply 36, no. 3 (2008): 135-41.

88. Kate Harcourt, Melanie Wacker, and Iris Wolley, “Automated Access Level Cataloging for Internet Resources at Columbia University Libraries," Library Resources \& Technical Services 51, no. 3 (July 2007): 212-25.

89. Marcia Lei Zeng and Jian Qin, Metadata (New York: NealSchuman, 2008).

90. Patricia Harpring, "CCO Overview and Description," Visual Resources Association Bulletin 34, no. 1 (Spring 2007): 34-44.

91. Beth M. Whittaker, "DACS and RDA: Insights and Questions from the New Archival Descriptive Standard," Library Resources \& Technical Services 51, no. 2 (Apr. 2007): 98-105.

92. Mary S. Alexander, "Core Cataloging and Metadata Standards and Best Practices," Science \& Technology Libraries 28, no. 1/2 (2008): 63-85.

93. Mary W. Elings and Günter Waibel, "Metadata for All: Descriptive Standards and Metadata Sharing Across Cultural Heritage Communities," Visual Resources Association Bulletin 34, no. 1 (Spring 2007): 12.

94. Ibid., 13.

95. Timothy W. Cole and Muriel Foulonneau, Using the Open Archives Initiative Protocol for Metadata Harvesting (Westport, Conn.: Libraries Unlimited, 2007).

96. Ibid., 185-86.

97. Ibid., 189.

98. Jane Greenberg and Eva Méndez, eds., "Knitting the Semantic Web," special issue, Cataloging \& Classification Quarterly 43, no. $3 / 4$ (2007).

99. Charles McCathieNevile and Eva Méndez, "Library Cards for the 21st Century," Cataloging \& Classification Quarterly 43, no. $3 / 4$ (2007): 30 .

100. Corey A. Harper and Barbara B. Tillett, "Library of Congress Controlled Vocabularies and Their Application to the Semantic Web," Cataloging \& Classification Quarterly 43, no. 3/4 (2007): 47-68.

101. Jane Greenberg, "Advancing the Semantic Web Via Library Functions," Cataloging \& Classification Quarterly 43, no. 3/4 (2007): 203-25.

102. Alistair Miles and Jose R. Pérez-Agüera, "SKOS: Simple Knowledge Organisation for the Web," Cataloging \& Classification Quarterly 43, no. 3/4 (2007): 69-83. 
103. Karen Coyle et al., "Framework for a Bibliographic Future," May 2007 rev., http://futurelib.pbworks.com/Framework (accessed Sept. 23, 2009).

104. Susannah Benedetti, Sue Ann Cody, and Arlene Hanerfeld, "Integrating a Digital Library and a Traditional Library: Librarians and Scientists Collaborating for Sustainability," Technical Services Quarterly 24, no. 3 (2007): 15-27.

105. Jim LeBlanc and Martin Kurth, "An Operational Model for Library Metadata Maintenance," Library Resources \& Technical Services 52, no. 1 (Jan. 2008): 54-59.

106. Melanie Feltner-Reichert and Marielle Veve, "Moving Beyond MARC: Initiating and Embracing Change in a Traditional Technical Services Department," Against the Grain 19, no. 5 (Nov. 2007): 28, 30, 32, 34.

107. Geoff Brown and Kathryn Harvey, "Adding Archival Finding Aids to the Library Catalogue: Simple Crosswalk Or Data Traffic Jam?" Partnership: The Canadian Journal of Library \& Information Practice \& Research 2, no. 2 (2007): 1-18.

108. Ibid., 13 .

109. A full list of the most recent editions of classification schedules is available at www.loc.gov/cds/classif.html.

110. Library of Congress Cataloging Policy and Support Office, Library of Congress Classification. E-F. History of the Americas (Washington, D.C.: Library of Congress, Cataloging Distribution Service, 2007): iii.

111. Mohinder Partap Satija, The Theory and Practice of the Dewey Decimal Classification System (Oxford, England: Chandos, 2007).

112. Doreen Sullivan, "DDC Gem," Australian Library Journal 57, no. 4 (Nov. 2008): 484.

113. Ia McIlwaine, The Universal Decimal Classification: A Guide to Its Use (The Hague: UDC Consortium, 2007).

114. Aida Slavic, "Use of the Universal Decimal Classification: A World-Wide Survey," Journal of Documentation 64, no. 2 (2008): 211-28.

115. Ibid., 224.

116. Rebecca Green, "Relationships in Knowledge Organization," Knowledge Organization 35, no. 2/3 (2008): 150.

117. Ibid., 158.

118. Robert N. Bland and MarkA. Stoffan, "Returning Classification to the Catalog," Information Technology \& Libraries 27, no. 3 (Sept. 2008): 55-60.

119. Richard Maker, "Finding what You're Looking for: A ReaderCentred Approach to the Classification of Adult Fiction in Public Libraries," Australian Library Journal 57, no. 2 (May 2008): 169-77.

120. Rachel Brett, "Classification Practice in Law Libraries: A Brief Survey," Legal Information Management 8, no. 1 (Spring 2008): 61-63.

121. David H. Elazar, "The Making of a Classification Scheme for Libraries of Judaica," Judaica Librarianship 14 (2008): 15-25. See also David H. Elazar and Daniel Elazar, A Classification System for Libraries of Judaica, 3rd. rev. ed. (Northvale, N.J.: Jason Aronson, 1997).

122. Elazar, "The Making of a Classification Scheme for Libraries of Judaica," 16.

123. Candy Schwartz, "Thesauri and Facets and Tags, Oh My! A Look at Three Decades in Subject Analysis," Library Trends 56, no. 4 (Spring 2008): 833.
124. Ibid., 834.

125. Ibid., 837.

126. Louise F. Spiteri, "The Structure and Form of Folksonomy Tags: The Road to the Public Library Catalog," Information Technology \& Libraries 26, no. 3 (Sept. 2007): 13-25.

127. Elaine Peterson, "Parallel Systems: The Coexistence of Subject Cataloging and Folksonomy," Library Philosophy \& Practice (2008): 1-6, http://unllib.unl.edu/LPP/e-peterson3 .pdf (accessed June 5, 2008).

128. Ibid., 5 .

129. James Sinclair and Michael Cardew-Hall, "The Folksonomy Tag Cloud: When is It Useful?" Journal of Information Science 34, no. 1 (2008): 15-29.

130. Ibid., 16.

131. Alireza Noruzi, "Folksonomies: Why Do We Need Controlled Vocabulary?" Webology 4, no. 2 (2007), www.webology .ir/2007/v4n2/editorial12.html (accessed June 5, 2008).

132. Ibid

133. Jeffrey Beall and Karen Kafadar, "Measuring the Extent of the Synonym Problem in Full-Text Searching," Evidence Based Library \& Information Practice 3, no. 4 (2008): 18-33, http://ejournals.library.ualberta.ca/index.php/EBLIP/article/ view/4081/3697 (accessed Mar. 16, 2009).

134. Ibid., 29.

135. Ben Christensen, "Minoritization Vs. Universalization: Lesbianism and Male Homosexuality in LCSH and LCC," Knowledge Organization 35, no. 4 (2008): 236.

136. Ben Christensen, "Minoritization Vs. Universalization: Lesbianism and Male Homosexuality in LCSH and LCC," Knowledge Organization 35, no. 4 (2008): 236, 238. See also Ellen Greenblatt, "Homosexuality: The Evolution of a Concept in the Library of Congress Subject Headings," in Gay and Lesbian Library Service, ed. Cal Gough and Ellen Greenblatt (Jefferson, N.C.: McFarland, 1990): 75-101.

137. Jonathan Furner, "Dewey Deracialized: A Critical RaceTheoretic Perspective," Knowledge Organization 34, no. 3 (2007): 165.

138. D. Vanessa Kam, "Subject Headings for Aboriginals: The Power of Naming," Art Documentation: Bulletin of the Art Libraries Society of North America 26, no. 2 (Fall 2007): $18-22$.

139. Ibid., 21.

140. Frank Exner (Little Bear), "North American Indian Personal Names in National Bibliographies," in Radical Cataloging: Essays at the Front, ed. K. R. Roberto (Jefferson, N.C.: McFarland, 2008): 150-64.

141. Kelly Webster and Ann Doyle, "Don’t Class Me in Antiquities! Giving Voice to Native American Materials," in Ibid., 18995 .

142. Ann Chapman, "Resource Discovery: Catalogs, Cataloging, and the User," Library Trends 55, no. 4 (Spring 2007): 91731 .

143. Sylvia D. Hall-Ellis, “Subject Access for Readers' Advisory Services: Their Impact on Contemporary Spanish Fiction in Selected Public Library Collections," Public Library Quarterly 27, no. 1 (2008): 1-18.

144. Ibid., 14.

145. Theresa A. Strottman, "Some of our Fifty are Missing: Library of Congress Subject Headings for Southwestern Cultures 
and History," Cataloging \& Classification Quarterly 45, no. 2 (2007): 41.

146. ShuYong Jiang, "Lost in Translation: The Treatment of Chinese Classics in the Library of Congress Classification," Cataloging \& Classification Quarterly 45, no. 1 (2007): 3-14.

147. Jung-Ran Park, "Cross-Lingual Name and Subject Access: Mechanisms and Challenges," Library Resources \& Technical Services 51, no. 3 (July 2007): 186.

148. Antje Bednarek, "The Colonial Bias: Library Classification in Aotearoa New Zealand," New Zealand Library \& Information Management Journal-Nga Purongo 50, no. 3 (Oct. 2007): 233-45. Note: The author's name is misspelled as Bednareks at the beginning of the published article and appears in this incorrect form in some indexes.

149. Timothy B. Powell, "A Drum Speaks: A Partnership to Create a Digital Archive Based on Traditional Ojibwe Systems of Knowledge," RBM: A Journal of Rare Books, Manuscripts, \& Cultural Heritage 8, no. 2 (Fall 2007): 167-79.

150. Ibid., 169.

151. Ibid., 176, 179.

152. Hope A. Olson, "How We Construct Subjects: A Feminist Analysis," Library Trends 56, no. 2 (Fall 2007): 509-41.

153. Ibid., 531.

154. Green, "Relationships in Knowledge Organization."

155. Mary Walker and Deb Kulczak, "Shelf-Ready Books using PromptCat and YBP: Issues to Consider (An Analysis of Errors at the University of Arkansas)," Library Collections, Acquisitions, \& Technical Services 31, no. 2 (2007): 61-84.

156. Ibid., 82.

157. Rebecca Kemp, "MARC Record Services: A Comparative Study of Library Practices and Perceptions," The Serials Librarian 55, no. 3 (2008): 379-410.

158. Shawne D. Miksa, "A Survey of Local Library Cataloging Tool and Resource Utilization," Journal of Education for Library \& Information Science 49, no. 2 (Spring 2008): 128-46.

159. Ibid., 145.

160. Ibid., 144

161. Martin L. Knott et al., "Catalog Information and User Expectations in an Amazoogle World: Too Much? Too Little?" Against the Grain 19, no. 5 (Nov. 2007): 40.

162. Rick Bennett et al., "VIAF (Virtual International Authority File): Linking the Deutsche Nationalbibliothek and Library of Congress Name Authority Files," International Cataloguing \& Bibliographic Control 36, no. 1 (Jan./Mar. 2007): 12-18.

163. Ibid., 12.

164. Elizabeth McDonald and Joyce Johnston, "Showtime! Cataloging and Providing Access to Streaming Video Records in the Online Catalog," Tennessee Libraries 58, no. 2 (2008): $1-5$.

165. Miao Jin and Ann Branton, "Online Cataloging Tools Versus Print Cataloging Tools," Southeastern Librarian 55, no. 3 (Fall 2007): 18-22.

166. Miksa, "A Survey of Local Library Cataloging Tool and Resource Utilization."

167. Joseph R. Nicholson, "The Impact of the Library of Congress" Series Decision on LSU Libraries Catalog: Minor Damage Now; Long-Term Prospects Less Bright," Louisiana Libraries 71, no. 1 (2008): 3-10.

168. Ibid., 9.
169. J. McRee Elrod, "The Case for Cataloguing Education," The Serials Librarian 55, no. 1/2 (2008): 1-10.

170. Ibid., 5 .

171. Daniel N. Joudrey, "Another Look at Graduate Education for Cataloging and the Organization of Information," Cataloging \& Classification Quarterly 46, no. 2 (2008): 137-81.

172. Ibid., 175.

173. Ibid., 178.

174. Ingrid Hsieh-Yee, "Educating Cataloging Professionals in a Changing Information Environment," Journal of Education for Library and Information Science 49, no. 2 (Spring 2008): 101.

175. Ibid., 93.

176. Ione T. Damasco and Melanie J. McGurr, "A Survey of Cataloger Perspectives on Practicum Experiences," Cataloging \& Classification Quarterly 45, no. 4 (2008): 43-64.

177. Joan P. Lussky, "Employer Demands for Cataloger and Cataloger-Like Librarians and Implications for LIS," Journal of Education for Library \& Information Science 49, no. 2 (2008): 116-27.

178. Lihong Zhu, "Head of Cataloging Positions in Academic Libraries: An Analysis of Job Advertisements," Technical Services Quarterly 25, no. 4 (2008): 49-70.

179. Ibid., 54 .

180. John W. Chapman, "The Roles of the Metadata Librarian in a Research Library," Library Resources \& Technical Services 51, no. 4 (Oct. 2007): 279-85.

181. Ibid., 283.

182. Karen Calhoun, "Being a Librarian: Metadata and Metadata Specialists in the Twenty-First Century," Library Hi Tech 25 , no. 2 (2007): 174-87.

183. Laura Kane McElfresh, "Serially Speaking: When a Journal Isn't a Journal: Patrons, Catalogs, and Monographic Series," Technicalities 27, no. 1 (Jan./Feb. 2007): 1, 11-13.

184. Sheila S. Intner, "Dollars and Sense: RDA: Progress or Problem?" Technicalities 28, no. 4 (2008): 1-15.

185. Jean Weihs, "Interfaces: Education for Librarianship in the Mid-20th Century, Part Two: Cataloguing, Classification, and Circulation," Technicalities 28, no. 5 (2008): 9.

186. Rebecca Donlan, “An Unfortunate Event for Series, Or, LC Outsourced You Back,” Reference Librarian 47, no. 98 (2007): 95-99.

187. Tom Adamich, "RDA (Resource Description and Access): The New Way to Say, 'AACR2," Knowledge Quest 36, no. 4 (Mar./ Apr. 2008): 64-69.

188. Sanford Berman, "One Book, Many Missed Opportunities: Or, Why Cataloging Matters (When It's Done Right)," The Unabashed Librarian, no. 149 (2008): 20-23.

189. Ibid., 23.

190. Brigid Burke, "The Grim Outlook for Cataloging," online posting, Aug. 16, 2008, Brigid's Blog, http://brigidburke.blogspot.com/2008/08/grim-outlook-for-cataloging.html (accessed Dec. 18, 2009).

191. Alex Wright, Glut: Mastering Information through the Ages (Washington, D.C.: Joseph Henry Press, 2007): 3.

192. Ibid., 182.

193. Barbara A. Mitchell, "Boston Library Catalogues, 1850-1875: Female Labor and Technological Change," in Institutions of Reading: The Social Life of Libraries in the United States, ed. 
Thomas Augst and Kenneth Carpenter (Amherst: Univ. of Massachusetts Pr., 2007): 119-47.

194. Ibid., 145.

195. Ibid., 147.

196. Pamela Bluh, ed., Commemorating the Past, Celebrating the Present, Creating the Future: Papers in Observance of the 50th Anniversary of the Association for Library Collections \& Technical Services (Chicago: ALA, 2007).

197. Michael Gorman, "The True History of AACR2, 1968-1988: A Personal Memoir, by One Who Was There," in Bluh, ed., Commemorating the Past, 69.

198. Ibid., 72.

199. Tschera Harkness Connell, “A Look at Fifty Years of Library Resources \& Technical Services," Library Resources \& Technical Services 51, no. 4 (Oct. 2007): 237-53.

200. Ibid., 248.

201. Angel Clemons and Tyler Goldberg, "Ohio Valley Group of Technical Services Librarians: A History," Serials Review 33, no. 2 (2007): 103-13.

202. Elizabeth Mangan, "Cartographic Materials: A Century of Cataloging at Library of Congress and Beyond," Journal of Map \& Geography Libraries 3, no. 2 (2007): 23-44.

203. Ibid., 24.

204. Vanda Broughton, "Henry Evelyn Bliss: The Other Immortal, Or a Prophet without Honour?" Journal of Librarianship \& Information Science 40, no. 1 (Mar. 2008): 46.
205. Ibid., 55 .

206. Ibid.

207. Louise McLeod, "Women in Australian Librarianship: The Example of Jean Fleming Arnot," Australian Library Journal 56, no. 3/4 (November, 2007): 322-34.

208. Ibid., 322, 328.

209. Thomas Augst, introduction to Institutions of Reading: The Social Life of Libraries in the United States, ed. Thomas Augst and Kenneth Carpenter (Amherst: Univ. of Massachusetts Pr., 2007): 18 .

210. J. H. Bowman, "Annotation: A Lost Art in Cataloging," in Cataloger, Editor, and Scholar: Essays in Honor of Ruth C. Carter, ed. Robert P. Holley (Binghamton, N.Y.: Haworth, 2007): 95-111.

211. Linda C. Ewbank and Ruth C. Carter, "An Interview with Ruth C. Carter," in Cataloger, Editor, and Scholar: Essays in Honor of Ruth C. Carter, ed. Robert P. Holley (Binghamton, N.Y.: Haworth, 2007): 19-38; Kathryn Luther Henderson, "The Story of Ruth: The Life and Contributions of Ruth C. Carter," in Cataloger, Editor, and Scholar, 7-17; Sandra K. Roe, Rebecca Culbertson, and Laurel Jizba, "Cataloging \& Classification Quarterly, 1990-2006," in Cataloger, Editor, and Scholar, 39-52. 